Portland State University

PDXScholar

\title{
Adult ESL Writing Journals: A Case Study of Topic Assignment
}

Kathryn Elaine Brunette

Portland State University

Follow this and additional works at: https://pdxscholar.library.pdx.edu/open_access_etds

Part of the Bilingual, Multilingual, and Multicultural Education Commons Let us know how access to this document benefits you.

\section{Recommended Citation}

Brunette, Kathryn Elaine, "Adult ESL Writing Journals: A Case Study of Topic Assignment" (1994). Dissertations and Theses. Paper 4738.

https://doi.org/10.15760/etd.6622

This Thesis is brought to you for free and open access. It has been accepted for inclusion in Dissertations and Theses by an authorized administrator of PDXScholar. Please contact us if we can make this document more accessible: pdxscholar@pdx.edu. 
THESIS APPROVAL

The abstract and thesis of Kathryn Elaine Brunette for the Master of Arts in Teaching English to Speakers of Other Languages were presented May 25, 1994, and accepted by the thesis committee and the department.

COMMITTEE APPROVALS:

$$
\text { Marjorie Terdal, Chair }
$$
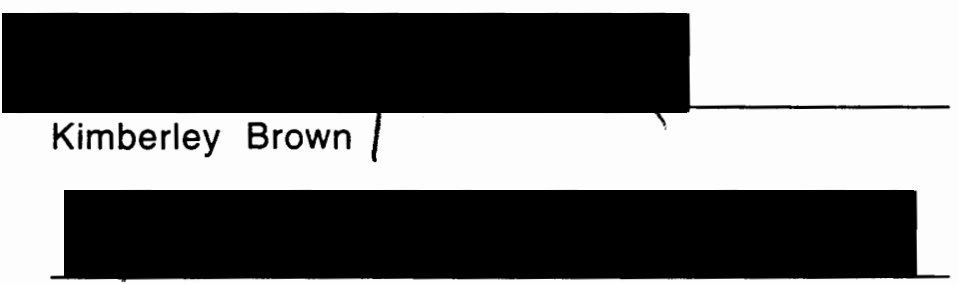

M. Jane Dresser

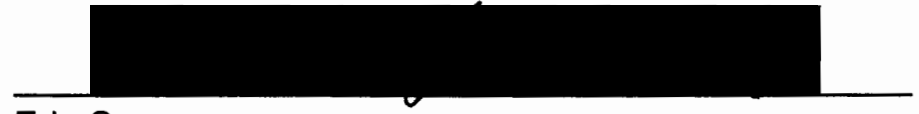

Eric Swenson

Representative of the Office of Graduate Studies

DEPARTMENTAL APPROVAL:

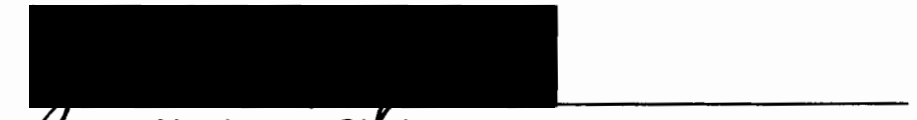

ames Nattinger, Chair

Department of Applied Linguistics

ACCEPTED FOR PORTLAND STATE UNIVERSITY BY THE LIBRARY

by

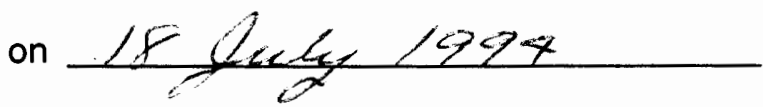




\begin{abstract}
An abstract of the thesis of Kathryn Elaine Brunette for the Master of Arts in Teaching English to Speakers of Other Languages presented May 25, 1994.
\end{abstract}

Title: Adult ESL Writing Journals: A Case Study of Topic Assignment.

Over the past ten years, the use of student writing journals has become increasingly widespread in the TESOL field. Such journals serve a wide variety of purposes: a cultural diary, a free writing exercise, a forum for reaction or comment on readings or classroom discussions, in addition to a form of teacher/student dialogue.

The main purpose of this study has been to determine the relationship of topic assignment to the quantity and quality of resulting entries. The data, 144 journal entries generated by ten adult ESL students over a period of ten weeks, were measured for length, in terms of total words and total number of T-units, and quality as assessed by the Jacobs profile (1981) which considers the following areas: content, organization, vocabulary, language use and mechanics. In addition, student reactions to instructor comments and attitudes toward journal keeping were explored in an end of term questionnaire.

It was found that, on a group level, the assignment of four specified topic types (A. Topics relating to class lectures and discussions, B. Topics relating class discussions to the students' respective cultures, C. Topics relating to class or personal experiences and $\mathrm{D}$. No topic assignment) did not appear to have any relationship with either the quality or quantity of writing. However, on an individual level, topic assignment did 
seem to have a relationship with the quantity of writing and in some cases, the quality as well.

In considering student reaction to instructor comments, all students reported reading instructor comments, but rarely responded to them. When considering topic assignment, $74 \%$ of the students stated preferring an assigned topic, yet $60 \%$ actually wrote more when given a free choice of topic. Also, on the individual level, students stated a variety of topic type preferences that roughly corresponded with an increase in entry length. Finally, students seemed to have a positive attitude toward journal keeping as $80 \%$ stated they would like to keep a journal next term. 
ADULT ESL WRITING JOURNALS: A CASE STUDY OF TOPIC ASSIGNMENT

by

KATHRYN ELAINE BRUNETTE

A thesis submitted in partial fulfillment of the requirement for the degree of

MASTER OF ARTS

in

TEACHING ENGLISH TO SPEAKERS OF OTHER LANGUAGES

Portland State University

1994 


\section{ACKNOWLDGMENTS}

I would like to thank my advisor, Marjorie Terdal, for her suggestions, support and efficiency and the members of my committee for their insights and encouragement.

I would also like to thank all the students who generously gave me permission to use their journals for this study. Without them, this study would not have been possible. 


\section{TABLE OF CONTENTS}

PAGE

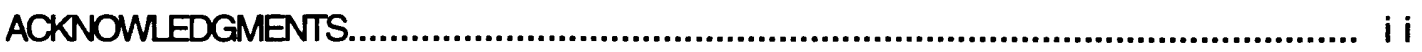

LIST OF TABLES

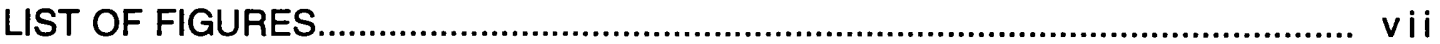

\section{CHAPTER}

I INTRODUCTION

Background................................................................... 1

Statement of the Problem................................................... 3

Questions for Research....................................................... 3

II REVIEW OF THE LITERATURE................................................... 6

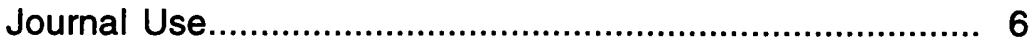

Effects of Task and Topic................................................... 11

Measures of Second Language Writing.................................. 15

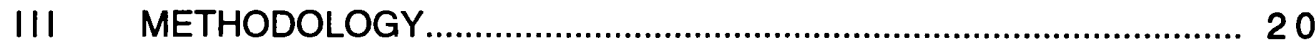

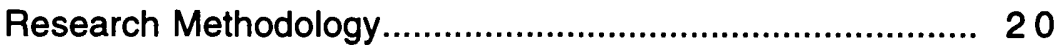

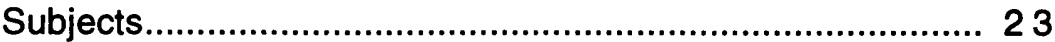

Analysis of Data............................................................ 26

IV RESULTS OF THE STUDY........................................................ 30

Group Results.............................................................. 30

Individual Results....................................................... 37

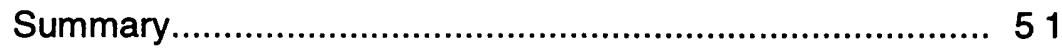


V DISCUSSION OF THE RESULTS................................................. 52

Relation Between Topic Assignment and

Quantity of Writing.................................................... 52

Topic Assignment and Quality of Writing..................... 57

Written Reaction to Teacher Comments........................... 58

Student Attitudes................................................... 59

Conclusion.............................................................. 61

VI CONCLUSIONS AND RECOMMENDATIONS..................................... 63

Topic Assignment and Journal Keeping : A Summary......... 63

Limitations and Difficulties............................................ 65

Recommendations for Future Journal Use......................6 67

Suggestions for Further Research with ESL Journals........ 69

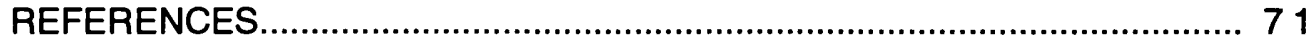

APPENDICES

A END OF TERM QUESTIONNAIRE..................................... 75

B JOURNAL HANDOUT ..................................................... 78

C CONSENT FORM FOR JOURNAL USE.................................... 80

D JACOBS ET AL. (1981) COMPOSITION PROFILE................ 82

E VASSILI'S RESULTS....................................................... 84

F INNA'S RESULTS ..................................................... 86

G YOKO'S RESULTS.................................................... 88

H JAMES' RESULTS ........................................................ 90

I ILENA'S RESULTS....................................................... 92

J THOMAS' RESULTS .................................................... 94.

K HISAYO'S RESULTS..................................................... 96 
L $\quad$ FRANÇOIS' RESULTS...................................................... 98

M DANNY'S RESULTS.................................................. 100

N NIKO'S RESULTS.................................................. 102

O TYPE A ENTRY SAMPLES............................................... 104

P TYPE B ENTRY SAMPLES.......................................... 107

Q TYPE D ENTRY SAMPLES......................................... 112

R TYPE C ENTRY SAMPLES.............................................. 117 


\section{LIST OF TABLES}

TABLE

PAGE

$1 \quad$ Winter 1994 Speaking and Listening Journal Topics..................... 22

II Questions Included on the End of Term Questionnaire...................... 23

III Group Averages for Topic Types................................................... 31 


\section{LIST OF FIGURES}

FIGURE

PAGE

1. Group averages of words according to topic type...................... 33

2. Group averages of T-units according to topic type...................... 33

3. Student preferences of topic assignment............................... 35

4. Student preferences of topic type........................................ 35

5. Length in words of Vassili's entries according to topic type........... 38

6. Length in words of Inna's entries according to topic type.............. 39

7. Length in words of Yoko's entries according to topic type............. 40

8. Length in words of James' entries according to topic type............ 42

9. Length in words of llena's entries according to topic type..............43

10. Length in words of Thomas' entries according to topic type........... 44

11. Length in words of Hisayo's entries according to topic type........... 46

12. Length in words of François' entries according to topic type......... 47

13. Length in words of Danny's entries according to topic type............ 48

14. Length in words of Niko's entries according to topic type............. 50

15. Individual variation according to topic type............................. 54 


\section{CHAPTER I}

\section{INTRODUCTION}

The following study explores the use of student journals in the adult ESL (English as a Second Language) classroom. In a case study setting, students' journals were collected over a ten week period and later analyzed in a quantitative manner to determine any possible relationship among assigned journal topics and the amount and quality of writing students produce in their journals. In addition, student input in the form of open ended questionnaires is integrated into the quantitative findings in order to present a more comprehensive view of journal use in the ESL classroom.

\section{BACKGROUND}

Over the past ten years, the use of student writing journals has become increasingly widespread at all levels of education ranging from the elementary to graduate level. Such journals serve a wide variety of purposes: a place for personal reflection and development, a cultural diary, a free writing exercise, a forum for reaction or comment on readings or classroom discussions, in addition to a form of teacher/student dialogue. Since student journals, hence referred to as journals, are used for such a wide range of purposes the formats and procedures for keeping and collecting journals also vary greatly as well. However, there are some consistencies. Journals generally consist of a collection of writings generated over the duration of the course and for the most part, students are encouraged to write freely and focus on content rather than form. The instructor's role is generally to collect, read and comment on the journals, which may or may not be graded. 
One of the underlying principles of journal use is that journals provide students a forum for informal individual contact with instructors, and with the help of instructors' comments and questions students can reacher a higher level of proficiency than they could independently or expand what Vygotsky (1978) termed the zone of proximal development or the level of ability that can be attained with the guidance or help of a more capable or skilled person.

In the Teaching English to Speakers of Other Languages (TESOL) field, journals provide a unique opportunity for both the language learner and the instructor to focus on communication and meaning rather than on grammatical or rhetorical form. Several studies have explored the use of journals with ESL students and concluded that they are useful in teaching all skill areas; grammar (Peyton, 1990) reading (Dolly, 1990; Nemoianu, 1992), general speech and communication (Bell, 1984), and writing (Lucas, 1988; Vanett \& Jurich 1990a \& b).

Journals in the ESL classroom can also serve as a way to relate language learning and personal experiences (Bell, 1984), as an avenue for authentic discourse (Dolly, 1990 ) or as a tool to explore student understanding of reading material (Nemoianu, 1992). Furthermore, they can create opportunities for teacher student dialogue (Peyton and Seyoum, 1988; Vanett and Jurich, 1990a). Finally, in elementary school settings, dialogue journals have been shown to produce writing greater in length and quality than standard academic writing since, in addition to providing an avenue for personal expression and language development, journals serve a truly communicative purpose (Peyton, Stanton, Richardson \& Wolfram, 1990).

While all these studies are helpful to the classroom teacher, they provide little in the way of documented evidence as to the effectiveness of adult student journals or to the attitudes of students themselves. In addition, the above mentioned studies do not 
directly address the issue of topic assignment or choice in journal use. This case study attempts to explore such issues in both a quantitative and qualitative manner.

\section{STATEMENT OF THE PROBLEM}

Having established the fact that journals are useful tools in the ESL classroom, additional research is needed to explore the influences of topic assignment and or choice, instructor's comments and questions, as well as student attitudes toward journal keeping as an important component of their language learning. All the areas mentioned above merit additional, or initial, research since, although many teachers incorporate journals into their courses, their use is rarely documented or evaluated by the instructor in a systematic may and may often be seen as a less important, side activity not meriting careful study. In addition, the majority of existing ESL journal studies are based on younger learners in K-12 settings and often focus on the merits and problems of journal keeping or compare formal writing to journal writing.

Nonetheless, having made use of journals in her past teaching experience, this researcher has noted considerable differences in length and quality of journal entries on an individual level as well as on a class level. This thesis studies the use of adult ESL student journals over a ten week term in the context of an academic intermediate speaking and listening class. The relationships among topic assignment and entry length and quality of completed entries is the primary focus of exploration. In addition, student attitudes toward assigned topics, specific entries and instructor comments will be explored as well as student attitudes toward journal writing in general. 


\section{QUESTIONSFORRESEARCH}

The guiding question for this study is:

In what way does the assignment of topic affect or influence the quantity and quality of writing produced in journals?

The following questions are specific inquiries to help in answering this question and address specific concerns of journal writing and its use in the classroom:

1. In a case study setting of intermediate academic ESL students' journals, on both a group and individual level, what is the relationship between the assignment of a topic and the length of a journal entry as measured by the number of (a) total token words per entry (which includes all words written as part of an entry) and (b) T-units? One T-unit, as defined by Hunt, consists of "a main clause plus all the subordinate clauses and clausal structures attached to or embedded in it" (1970, p. 4).

2. What is the relationship on both a group and individual level between the assignment of a topic and the quality of a journal entry? (Qualitative measures assess the overall quality of the entry in terms of content, organization, vocabulary, language use and mechanics as measured by the Jacobs, Zinkgraf, Wormuth, Hartfiel and Hughey (1981) writing proficiency guide, Testing ESL Composition: A Practical Approach here after referred to as the Jacobs profile) 3. On an individual level, what is the relationship of average T-unit length in terms of average words per T-unit and the quality as assessed by the Jacobs profile score?

4. What is the written reaction of students to instructor comments in terms of frequency and length? 
5. Based on information gathered in questionnaires at the end of the term, which type of assignment topics do the students seem to prefer?

6. How do students feel about journal writing as an assigned task and how do they feel about the quality of writing produced in journals?

7. Do questionnaire responses correspond with quality assessments made by the researcher?

This study uses a combination of qualitative and quantitative measures on data collected over a ten week period from intermediate university level ESL students. In addition to this data, the researcher's observations, student written responses to questionnaires and excerpts from journal entries were considered as qualitative data. The goal of this study is to determine the effects of topic assignment in the context of journal use and provide guidelines to effective use of journals in the university level ESL classroom.

The following chapters of this thesis include a review of related research and literature in both the TESOL and first language (L1) education fields, a description of the research methodology and analysis techniques employed in the study, a detailed summary of the results, a discussion of the results and limitations of the study, and recommendations for journal use in adult ESL classrooms. 


\section{CHAPTER II}

\section{REVIEW OF THE LITERATURE}

The following chapter is a summary of literature relevant to this study. Project descriptions of ESL and first language (L1) journal use are summarized to provide an understanding of the different types of and contexts for journal use. A review of ESL journal studies discusses currents trends in research and demonstrates the need for this study. The effects of task and topic are explored from both a $L 1$ and second language (L2) perspective. Finally, both quantitative and qualitative measures of L2 writing are reviewed, and the measures selected for this study are discussed in detail.

\section{JOURNAL USE}

\section{Second Language Student Journal Use}

Documented use of journals is relatively new in the TESOL field. Most studies have been presented at conferences or summarized in teaching guides and are rarely published in scholarly journals. Even so, two distinct types of literature have emerged, project descriptions and studies measuring a variable.

Project Descriptions. Project descriptions and guidelines are the most common form of literature on student journals and are of importance in describing the various documented uses of journals in the classroom. Bell (1984) summarizes her use of journals in conjunction with the language experience approach. According to Bell, this approach uses the student's language experience as a source for classroom material, much like some of the activities used in the Whole Language Approach in L1 classrooms (Goodman, Bird and Goodman, 1991). 
Bell made use of several activities which included writing down stories from the student's homeland, expanding on the stories, keeping a journal, creating pictures to accompany the stories and using the material for further classroom discussion. The keeping of journals was an informal way of transforming L1 experiences into English. Bell concludes that journals are a particularly appropriate format since the student may feel less restricted by formal writing conventions and find journal writing easier to expand upon.

Dolly (1990) promotes journals as a forum for teacher-student interaction in large classrooms. Such journals give students an opportunity to express themselves and react to reading material. In turn, teacher comments may stimulate further discussion of a topic or clarify points of confusion.

In another project description, Nemoianu (1992) documents the successful incorporation of journals in reading classes. In a freshman ESL writing and literature course, students were asked to make comments in their journals after an initial and later second reading of a passage.

She found that the first entries were more expressive, making comments on difficulty, personal reaction, or relevance to their experience while the second entries were more controlled and formal in nature. Nemoianu suggests that expressive writing allows students to explore their thoughts and better understand the readings before attempting a formal analysis of the passage. In conclusion, she advocates the use of journals to facilitate understanding of readings and to help students create their own meaning.

Another description and classroom guideline for journal use (Vanett and Jurich 1990a) views journal writing as an important part of the writing process since it encourages students to draw on their life experience rather than requiring them to internalize and transform new information. In general, Vanett and Jurich recommend 
assigning "broad topics with a personal scope" (1990a, p. 26) that permit students to develop the direction of their own topics. They continue by stating that this practice promotes student autonomy and allows them to select topics that interest them. Finally, it is suggested that journal assignments be preceded by pre-writing activities and not required when other written work is due since this may create a conflict.

Journal Studies. The other major body of literature concerning ESL journals is case study research that primarily focuses on classroom practices and use of journals. However, the majority of journal studies, with the exception of the following, Lucas (1988), have been primarily concerned with journal use in the elementary or middle school classroom and several studies have been conducted in the same classroom with the same instructor (Shuy, 1993; Stanton, 1993, Peyton \& Seyoum 1988; Peyton, Stanton, Richardson \& Wolfram, 1993).

Lucas' research (1988) provides insights into topic selection, individual variation and the process of developing what she terms a "written genre" (p. 2). In a study of university level adult ESL students, Lucas analyzed the students' journal writing in terms of five features: functions, content, audience, organizational form and linguistic form. Some students were found to embrace certain topics and continue writing on them for several entries while other students would write very little. She concluded that individual differences such as personality and previous writing experience had a greater effect on writing than cultural background but did not discuss the possible influence of topic. Still, her study demonstrates that student journals are a valid source of data for TESOL research and that the role of topic needs to be further explored.

In a study of teacher response to sixth grade ESL students' journals, Peyton and Seyoum (1988) found journal entries tended to be better in quality and longer in terms of T-units (as defined by Hunt as: "a main clause plus all the subordinate clauses and non 
clausal structures attached to or embedded in it" $(1970, p .4))$ when the teacher responded to topics with statements and opinions rather than introducing other topics or asking questions. The researchers, however, do not claim that the increased number of T-units indicated a higher level of syntactic complexity (as did Hunt) but only a willingness to participate.

In a study exploring the effect of writing task on sixth grade ESL students' written production Peyton, Stanton, Richardson and Wolfram (1990) found that the quantity and maturity of writing produced in dialogue journals was at least equivalent and in some cases superior to formal assigned writing. The researchers suggest that this may be due to the communicative nature and authentic purpose of dialogue journal writing.

The view that journal style writing may generate greater student interest and result in a higher level of student interaction is supported by Reyes (1991) in a study of journal use with bilingual children. The study indicated that journal style writing in which students were allowed to choose and develop their own topics resulted in greater cooperation and produced a greater quantity of writing than other more formal types of writing. Furthermore, the findings suggest that assigning or imposing a topic negatively affects student writing since the student may not have any personal interest in it or not find the topic relevant to their daily lives.

In considering the types of interaction that occur in student dialogue journals, Shuy's (1993) study suggests that given a free choice in the development of topic, ESL students tend to use journals first and foremost to report personal facts $(30.6 \%$ of occurrences) and opinions (28.5\% of occurrences). After these two functions, students tend to use journals to report general facts $(20.1 \%$ of occurrences) and on an infrequent basis to evaluate and ask for information (respectively, $5 \%$ and $4.6 \%$ of occurrences) (p. 136). 
When investigating the language use of teachers in sixth grade student dialogue journals, studies by Shuy (1993) and Stanton (1993) indicate that teachers generally do adjust the language used in their responses according to the perceived proficiency level of the student. Interactional features that are of particular interest include: question form, topic marking and order. The teacher consistently adjusted these features according to the perceived level of proficiency of the student (Stanton). This shows that journals do serve the students' need for comprehensible input needed for language acquisition (Krashen, 1982) and that teachers are capable of adjusting their input almost unconsciously (Stanton).

\section{First Language Speech Journals and Written Production}

Successful use of journal writing has also been documented in many first language (L1) settings. Of particular interest to this research proposal, Schwartz (1989) documents the use of student writing journals in a college freshman level speech course, a setting similar to the one used in this study. Both in class and home journals offered students a non-threatening means of class participation and facilitated future class discussions, since entries served to develop understanding of and opinions on a given topic. Students were encouraged to consider journal writing tasks as a process of discovery rather than a practice exercise in correct writing. Furthermore, when later questioned at the end of the term, the majority of students were found to favor the journal writing format and to find it helpful in their understanding of course topics.

The results of the Schwartz study (1989), which showed journal writing to be helpful in understanding course material, are in accord with both L1 and L2 promoters of the writing process. Flower and Hayes (1980), Raimes (1985) and Zamel (1983) assert that writing is the process of discovery and that skilled writers first explore and clarify ideas before attending to language related concerns. Related to the exploration of ideas in writing is Sweigart's (1991) study of the effects of discussion groups on 
writing in a 12th grade $L 1$ composition class. Sweigart found that small group discussion of a composition topic prior to writing resulted in improvement of writing in terms of clarity of thesis and elaboration of opinion with supporting evidence. Hence, it may be concluded that oral discussion and written exploration have a positive effect on the development and understanding of class and composition topics. However, it is not clear to what degree the task or topic assignment influences the quality or quantity of writing produced.

\section{EFFECTS OF TASK AND TOPIC}

It is generally agreed that teachers' questions have an important effect on their students' responses and understanding of class information. Teachers' questions are usually directed with a specific type of response in mind requiring varying levels of cognitive complexity. According to Bloom's taxonomy (1956), instructional questions vary in degrees of cognitive complexity. Recognition, recall and comprehension of factual information are at a lower level of complexity and require less thought processing, while analysis, synthesis, abstraction and evaluation demand more complex cognitive processes. Hence, it is generally concluded that questions requiring a higher level of cognitive complexity are more helpful in learning than questions merely requiring recall or recognition (Zhang, 1983).

In an ESL setting, the form and complexity of questions also have great importance since the student response requires language processing in conjunction with thought processing. While a recall question may seem easier to answer, it also in many ways limits the amount and complexity of language the student can produce in response. Indeed, Brock (1986) concluded that responses to referential questions, open ended style questions eliciting information unknown to the instructor, tend to result in better oral performance than do display questions, those with a set answer known by the 
instructor. However, in responding to referential questions it is equally important that students have some sort of background knowledge or frame of reference.

Studies in cognitive science (Piaget, 1954; Vygotsky, 1962) have demonstrated that an individual's background knowledge or experience influence the construction of meaning of a given event. Furthermore, in both $L 1$ and $L 2$ reading studies (see, for example, Anderson \& Pearson, 1984; Bernhart, 1984; Johnson, 1982), the comprehension process is viewed as dependent upon the relationship between the reader's background knowledge and the information contained in the text.

In written production, subject matter knowledge has also been found to be influential in performance. Cultural familiarity and prior knowledge have been demonstrated as a positive influence on university ESL students' writing (Winfield \& Barnes-Felfeli, 1982). Students produced longer writing in terms of total length and higher quality writing in terms of grammaticality. This suggests that topics that allow students to relate to their respective cultures may result in more accurate indications of L2 writing proficiency.

Nonetheless, the benefits of background knowledge are not uniquely limited to cultural contexts. In a related study of 105 ESL graduate students, Tedick (1990) demonstrated that writing on a field specific topic generally resulted in superior performance in terms of holistic measures, length and error free T-units indices than did general writing prompts. Furthermore, lower level proficiency students seemed to benefit more from their use of background knowledge in the field specific topic prompts than the advanced level writers. This suggests that on an individual level background knowledge may have varying effects depending on the proficiency level of the writer.

The belief that the communicative nature of dialogue journals contributes positively to quantity and complexity of ESL student writing is also supported by a comparative study of dialogue journals and literature logs (Reyes, 1991). In a study of 
ten bilingual sixth graders Reyes directly links personal background knowledge to success in journal writing. She asserts that in using dialogue journals students are more effective in constructing meaning and generally write more when they could choose their own topic and were able to address a real audience. In contrast, the writing in literature logs usually involves writing about someone else's experiences which may have less meaning than the students' own personal experiences.

Task and topic are closely related, one often defining the other in writing activities. Hence, the task can also affect quality and quantity of written production. In a study of adult, advanced ESL writers, Zhang (1987) found that the cognitive complexity of the writing task is an important factor when judging writing quality. Questions with a higher level of complexity received more attention by the writer, in the form of longer responses (number of words) and more use of complex language (clauses and structures) without proportionately more errors. These results suggest that meaningful, interesting writing topics do encourage student participation and effort in writing assignments.

\section{Other Factors}

In addition to task and topic, other factors generally considered as important in L2 writing include: audience, the effects of translation on invention and first language influences. The role of audience has been the focus of several studies. In a study of ESL writing processes, Raimes (1985) found that the majority of subjects ignored the hypothetical audience and tended to write for an abstract teacher audience. Yet, in journal writing, instructor response including personal experiences and reflections helped students better address the concerns of audience, purpose and content in their writing (Vanett and Jurich, 1990b). In addition, Reyes' study (1991) also supports this belief. She found that addressing reading journals in a letter format served as an ice breaker and allowed students to approach the topic on a more personal level. Although 
not dealt with in length in this study, the role of perceived audience, and purpose and topic are all factors in ESL writing and merit further consideration.

The importance of developing ideas is mentioned in Spack's (1984) article on invention strategies and college ESL writers. Spack firmly believes that invention, the creation of a wide range of views and approaches to the topic along with appropriate vocabulary is essential in ESL writing. However, invention and development of ideas can be particularly difficult for ESL students since the English vocabulary necessary is not directly linked to their past experiences. This sometimes presents problems in rendering images and thoughts concrete (Spack, 1984).

Several studies (see, for example, Kobayashi \& Rinnert, 1992; Lay, 1983) have explored the effect of translation on the quality of $L 2$ writing and found that translation of key ideas and vocabulary usually has a positive influence on L2 writing.

Furthermore, since the linking of past $L 1$ cultural experiences is viewed as helpful to L2 writing (Winfield \& Barnes-Felfeli, 1980) linking L2 vocabulary to concrete L1 experiences may prove to be helpful as well.

Finally, the influence of the students' first language is often said to play a role in L2 writing, especially in the case of students who come from cultures with an oral tradition (Hansen-Strain, 1989). Students coming from an oral tradition were generally more personal in their approach to writing and used first and second person references much more frequently, while Asian students tended to be more distanced in their approach to writing. This may be a consideration in using journals in the classroom. 


\section{MEASURES OF SECONDLANGUAGE WRTTNG}

\section{Background}

In discriminating among levels of second language writing proficiency or levels of writing performance, there are three commonly accepted techniques: holistic evaluation, analytical scoring and primary trait scoring (Brown \& Baily, 1984). Holistic and analytical evaluation focus more on communication of meaning while primary trait scoring focuses on rhetorical traits and intended audience. All three of these approaches attempt to measure the overall quality of a writing sample and are subjective in nature in that they are generally rated on a scale ranging from excellent to poor and are subject to the rater's judgment.

Although these subjective approaches are most commonly used today, objective, quantitative measures also exist. For the most part, they rely on objectively measured structural features such as sentence length and error frequency. The theory underlying these methods and the advantages and disadvantages of several systems are reviewed in the following section.

\section{Qualitative Measures}

Most qualitative measures result from the attempt to look at a writing sample in a holistic fashion considering the overall merit of the work. Brown and Baily (1984) define holistic evaluation as a general system of evaluation which generally rates a writing sample on a 4 to 8 point scale, be it letter grades $(A-F)$, or plus $(+)$, check plus $(v+)$, check $(v)$, minus $(-)$ system. In addition, holistic evaluation ranks or judges writing ability without tallying or considering certain types of errors (Perkins, 1980).

Holistically evaluated writing samples are often organized in a rank order comparing more proficient students with less proficient students. Such evaluations 
focus less on the presence or absence of certain traits or level of development and view the composition as a whole (Brown \& Baily, 1984). Holistic evaluation is most commonly used in the classroom or case study context. However, although a holistic evaluation is considered a valid and direct method of assessing and ranking writing proficiency, it is somewhat subjective and requires a serious time commitment to evaluator training (Brown \& Baily). Furthermore, since truly holistic evaluations do not consider separate categories of merit, scores resulting from such measures cannot account for differences in content, development, vocabulary or language use.

Analytical writing evaluation is closely related to and often confused with holistic evaluation. Indeed, many early descriptions of so called holistic writing evaluation are in fact analytical in nature (Brown \& Baily). The isolation of one or more characteristics typical to writing is the basis of analytical writing evaluation. Characteristics are judged or scored separately and later averaged together (in a variety of ways, depending upon the exact method) to result in a final comprehensive score. Initially interrater reliability was a major concern in using this type of system. However, by means of precisely written scoring guides and careful training a highly acceptable level of interrater reliability has been established (Greenberg, 1985; Jacobs, Zinkgraf, Wormuth, Hartfiel \& Hughey, 1981; Reid \& O'Brien, 1981).

An early analytical evaluation system for ESL writing which was initially considered "holistic" was the method used by Reid and O'Brien. This system is less complex and perhaps closer to a truly holistic evaluation than the other analytical systems discussed in this section simply because it considers only three areas: organization, content and English structure. Furthermore, these three areas are scored as excellent, good, average, fair or poor according to a general description rather than a precise numerical scale. However, in rating a large number of writing samples such a 
non numerical system presents problems in averaging scores or comparing groups of scores.

Another analytical ESL composition evaluation system is the Testing ESL Composition: A Practical Approach guide developed by Jacobs et al. (1981). Although the authors consider it "holistic" since it considers the whole composition, by Brown and Baily's (1984) definition it is more analytical in nature since it considers the separate areas of: content, organization, vocabulary, language use and mechanics (Jacobs et al.). Furthermore, each area is scored on a separate point scale (13 to 30 for content, but 1 to 5 for mechanics) which consists of four major levels (excellent to very good, good to average, fair to poor and very poor) each of which has its own criteria (see appendix D).

The scores for each category are later combined for an overall score that may range from 34 (minimum) to 100 (maximum). Although this may not be truly holistic, the creators feel that a categorized, well defined scoring system is necessary to minimize discrepancies among raters, individual inconsistencies, judgments on expectations and differences in areas of importance (i.e. style, word choice, grammar, organization etc.). The Jacobs profile well suits the needs of this researcher as well as writing placement needs since it considers the quality of writing samples in terms of individual characteristics and scores them in a quantifiable manner that facilitates comparison and averaging of numerous compositions or, in the case of this study, journal entries.

\section{Quantitative Measures}

Although the previously mentioned analytical style systems are now widely accepted and used, they are relatively new to the realm of writing evaluation. Prior to 1980 more objective, quantitative measures, such as T-units were used to judge writing performance in both first and second language composition. Initially developed for first language analysis, T-units are defined as an independent clause and any 
associated dependent clauses, i.e. clauses attached to or embedded in it (Hunt, 1970). Increased T-unit length (number of words per T-unit) is seen by some as an index of the development of syntactical maturity in writing since it would demonstrate increased ability to subordinate and reduce clauses (Gaies, 1980).

However, even in first language research, T-unit length does not account for many problem areas in writing such as excessive coordination or subordination (Ney, 1966). In second language research, the use of T-units poses even more problems. One primary concern relative to second language use is the strategy of circumlocution, or the practice of talking around a word or concept, which may account for greater T-unit length due to a lack of concise vocabulary (Moffet, 1968).

Another major concern when considering T-units in second language learning is the frequency of language related errors and incorrect subordination or coordination in forming T-units (Larsen-Freeman \& Strom, 1977). In the case of low proficiency writers, the high frequency of language related errors makes T-unit evaluation difficult if not impossible. Furthermore, the ratio of error free T-units to total T-units appears to be more important than T-unit length as an index of language proficiency.

Also, the definition of errors themselves is a question of debate. Larsen-Freeman and Strom include all errors in evaluating T-units. However, Vann (1978) takes a more tolerant approach considering only errors interfering with meaning or basic sentence structure and morpho-syntactic or lexical errors as significant. Gipps and Ewen (1974) take another approach in judging T-units. Mean T-unit length is considered in conjunction with an intelligibility rating ( 0 being unintelligible, 1 being partially intelligible, 2 completely intelligible and 3 completely accurate). Finally, there are different aspects of T-units to consider. The number of T-units and the number of words per T-unit are perhaps the most commonly used objective measures while clauses per main clause and words per clause are another consideration. For the 
purposes of this study the number of T-units is used as a measure of entry length. In addition, T-unit length in term of words per T-unit is used to compare an individual's writing style variations among journal entries.

\section{Quantitative Versus Qualitative Measures}

Perkins (1980) compares the holistic scoring of ESL compositions with objective measure scores obtained from T-unit evaluations. He concludes that the number of words per error free T-unit is the most discriminating measure among the holistic rated compositions. The number of error free T-units per composition, errors per T-unit and total errors correlate with the holistic evaluations as well. Hence, Tunit length in itself does not correspond with a higher holistic evaluation and would perhaps not be seen as a measure of second language proficiency. Furthermore, the majority of second language studies correlating two or more factors with the use of Tunits have been inconclusive, not showing any correspondence between $T$-unit length and other types of evaluations.

Nonetheless, the ability to write a greater amount of text using longer and more complex sentences is often a consideration in analytical evaluations. Reid and O'Brien (1981) mention quantity in their guide for evaluating content. Jacobs et al. (1981, p. 95) include "effective complex constructions" as a criterion for an excellent rating in their language use category. This seems to indicate that in fact T-unit length and or complexity does indirectly play a part in even holistic or analytical evaluation by influencing the judgment and scoring of the rater.

This review of literature has provided an overview of current writing proficiency measures, the perceived effects of topic and task in educational settings and state of ESL journal research. All of these areas have been considered to some degree in this study's research methodology and analysis of data which are detailed in the following chapter. 


\section{CHAPTER III}

\section{METHODOLOGY}

\section{RESEARCH METHODOLOGY}

The methodological design used in this case study was a combination of quantitative and qualitative measures. The quantitative measures explore the relationship of a variable, topic type, with the amount of writing produced in ESL student journal entries and the resulting Jacobs profile (1981) scores. The latter are used to determine the influence of topic on the quality of the journal entries. In addition, qualitative aspects of journals, such as content, responses to instructor comments and unprompted interaction, are explored in conjunction with the analysis of questionnaire responses.

\section{Generation and Collection of Data}

The researcher collected the necessary data for this study with the cooperation of ten intermediate ESL speaking and listening students during a recent ten week term at a large West Coast university. In her role as class instructor, the researcher required students to keep journals throughout the term and collected them on a weekly basis for comment and verification of completion. For the purpose of this study, the instructor assigned four specific topic types. Assignments were made on a bi-weekly basis and journals were collected once a week.

The following is a summary of the topic types:

A. Entries reacting to lectures and class discussions. 
B. Entries linking the lectures or class discussions to the students' cultural or life experience.

C. Entry based on current class or life experience, e.g. "Group Presentation Experience" or "Communication Experience with an American"

D. Entry of student's choice, no assigned topic.

The researcher's goal was to explore the quality and length of the entries resulting from the above topic type assignments for the group as a whole, as well as within individual journals. To achieve this goal, a detailed log of topics was kept (see Table I) as well as a general description of related topics discussed in class; in addition students were instructed to date and title their entries so they could be readily identified. Then the data, all journal entries for the entire ten weeks of the term, were photocopied with the permission of the participants and later analyzed by the researcher as described in the analysis section of this chapter.

\section{Questionnaires}

At the end of each term, all students in the course were asked to reflect upon their journals and given an optional, open ended questionnaire to complete at home. The questionnaires were used to gain an insight into their topic preferences and attitudes toward journal assignments as well as a basis for individual comparison for the qualitative assessment made by the researcher. Table II is a summary of the questions included on the questionnaire. For a copy of the questionnaire see Appendix A. The first three questions explore the student's preference of topic type. Questions four and five ask the student to focus on specific entries that may later be compared to the response in question one and to the Jacobs profile analysis of the researcher. Questions six and eight explore the amount of time students devote to journals and their attitudes toward journal keeping compared to other writing. 


\section{TABLE I}

\section{WINTER 1994 SPEAKING AND LISTENING JOURNAL TOPICS}

\section{TOPIC TYPES}
(A) Class Topic relating to lecture or discussion.
(B) Topic relating student's culture to class discussion or lecture.
(C) Personal life or class related experience.
(D) No assigned topic.

\# Date Title/Topic type

1. $1-10 \quad$ Breakfast in Your Country.

2. 1-12 Importance of Meals (A)

3. 1-14 What You Learned in Class (Martin Luther King Jr. Lecture) (A)

4. $1-17 \quad$ Your Choice (D)

5. $1-21$ Divorce, Your Opinion (A)

6. 1-24 Asking for Advice (C)

7. $1-28 \quad$ Immigration Trends in Your Country (B)

8. $1-31 \quad$ Your Choice (D)

9. 2-4 Communication Experience with an American (C)

10. 2-11 Group Presentation Experience (C)

11. 2-14 Reason for Social Change in Your Country (B)

12. $2-18$ Your Choice (D)

13. $2-21 \quad$ Interview Experience (C)

14. $2-25$ Religion in America (A)

15. $3-2$ Things I Wish I Knew Before Coming to America (C)

16. 3-4 Manners/Customs in Your Country (B) 


\section{QUESTIONS INCLUDED ON THE END OF TERM QUESTIONNAIRE}

1. When you write in your journal, do you like to have the teacher give you a topic, or do you like to choose your own topic?

2. What kind of topic do you like writing on most: class topics, relating my culture to class topics or my life/class experiences?

3. Why do you prefer this topic?

4. Which journal assignment do you think is the best?

5. Which journal assignment did you enjoy writing the most?

6. How much time do you spend on your journal entries?

7. Do you read the teacher's comments? If so, do you answer back? Why or why not?

8. Do you prefer journal writing or essay writing? Why?

9. Have you ever written in a journal before you took this class? If yes, where?

10. Do you keep a personal journal? (not for class) If so, do you write in English of your native language?

11. Would you like to keep a journal next quarter? Why or why not?

12. What did you like or not like about using journals this quarter?

(Students were given two to three lines to respond to each question.)

Student reactions to teacher comments are investigated in question seven. Questions nine and ten focus on previous journal writing experience. Finally, questions eleven and twelve provide a student perspective on future journal use.

\section{SUBJECTS}

The ten subjects providing data for this study were enrolled in a ten week, intermediate Speaking and Listening course that is part of a university level ESL 
program. Six of the students had been enrolled the term before and had previous experience in journal writing in previous courses. The remaining four students were new to the ESL program and had no experience in ESL journal writing.

\section{Recruitment of Subjects}

Participation in the study was voluntary although journal writing was required for all students enrolled in the course. At the second class meeting the purpose and practice of journal keeping was explained (see Appendix B for an example of the handout given to the class). Students were required to write about a page per entry but were encouraged to write as much as they thought necessary to address the topic.

In the second week of the term students were asked if they would grant the researcher permission to use their journals for her graduate thesis research. The general purpose of the study was explained and permission slips handed out to everyone in the class (for a copy of the permission slip, see Appendix C). The identity of the subjects was promised to be kept confidential and the majority of students granted their written permission. Since the subjects were selected on a voluntary basis, willingness to participate and enrollment in the course were the major factors in the subject selection process. In addition, a proportional representation of gender and nationality was attempted.

The nationality and gender of the participants is as follows: three female Japanese students; three Taiwanese students, two male and one female; one Indonesian male; two Ukrainians, a female and male; and one male student from Benin (in West Africa).

Language ability, as measured by the Michigan Test or other such tests and length of time spent in the United States was disregarded in the selection of subjects since placement in the same level suggests a certain degree of conformity in proficiency. Furthermore, research has suggested that previous writing experience in the $L 1$ is generally a more important indicator of writing ability than the time spent in the 
country or general proficiency scores except in the case of extremely low level or highly advanced students (Cumming, 1989; Raimes, 1987).

\section{Individual Student Profiles}

The following students have been given pseudonyms to protect their identity.

Yoko. Yoko, a female Japanese student, was approximately 19 years old at the time of the study. She had been in the ESL program for two terms prior to the study and had previous journal writing experience in at least two other ESL courses. At the time of the study she was enrolled in one other ESL class and one P.E. class and had plans to return to Japan and finish her undergraduate degree in English.

Hisayo. Hisayo, a 19 to 20 year old Japanese female student, was enrolled full time in ESL classes. She was repeating the class, and had been enrolled in ESL classes for several terms and had some previous journal keeping experience. She was a noticeably quiet student who rarely spoke in class or group discussions.

Niko. Niko was a part-time Japanese student who was taking ESL classes for her own personal enjoyment. She already had earned an undergraduate degree in her country and would be considered a skilled L1 writer. She was in the U.S. with her husband, who worked at the Japanese consulate, and enjoyed the social benefits of such a position.

James. James, a full time, Taiwanese male student in his late 20 's, had one term of journal keeping experience. At the time of the study, his plans were to continue his studies and earn a degree from a U.S. university.

Thomas. Thomas was a male, Taiwanese student in his mid 20's. As an admitted full time graduate student, he enrolled in ESL by his own choice. Although he was taking the class with a Pass/No Pass option, he was rarely absent and completed the majority of all class assignments, including his journal.

llena. Ilena, a female Taiwanese student, was enrolled full time in the ESL program at the time of the study. She had two terms of previous journal keeping 
experience in other ESL classes. At the time of the study, she was approximately 20 years old and planned to return to Taiwan to work in the near future and had no academic plans in the U.S.

Danny. Danny, a 19 year old Indonesian male, was also enrolled in the ESL program the previous quarter and had journal writing experience. At the time of the study, he was a full time student and planned to pursue an undergraduate degree in the U.S.

Inna. Inna, a Ukrainian female, was in her late 20's at the time of the study. Although she is a non-native resident, she was enrolled full time in ESL classes. She also was one of the few students with children and other responsibilities. She had no previous journal writing experience.

Vassili. Vassili was a full time student in his thirties from the Ukraine. He was unusual in the fact that he was a U.S resident and had a Masters degree in his country. He was also one of the only students who worked and had to take care of a family in addition to taking classes.

Francois. François, a graduate student from Benin in West Africa, was enrolled full time in ESL classes and hoped to start his graduate courses in the fall. He, too, may be considered a skilled writer as he has had newspaper articles published in his $L 1$, French. This is noteworthy since French has many cognates and is relatively similar in structure to English, which may facilitate his writing.

\section{ANALYSIS OFDATA}

The data were analyzed with descriptive statistics, with means calculated for various sets of data. General trends among the journals of the study group are recorded in addition to trends among the individual participants' journals. Missing journal 
entries were noted, but not considered in the averages. No attempt to account for missing journal entries was made.

\section{Quantitative Analysis}

The length of each entry was measured in two ways, by the number of token words or total number of words and the number of T-units written. For the purposes of this study a T-unit was defined in accordance with Hunt's definition "a main clause plus all the subordinate clauses and non clausal structures attached to or embedded in it" $(1970$, p. 4). Averages for each topic type were calculated on a group basis as well as an individual basis. The average length for a given entry was calculated by adding the total number of words written by all the participants then dividing the sum by the number of completed entries and rounded to the tenth of a decimal. To calculate the average number of words according to topic type, all entries were grouped according to topic type. Then, the total word count was added, and the sum divided by the number of completed entries for a given topic type. The same procedure was used to calculate the average number of T-units per entry. Missing journal entries were noted but not included in the calculation.

Individual trends in entry length were averaged in a similar manner; the length for each entry was calculated then averaged according to topic type to determine individual variations. These variations, if worthy of notice, were then compared with responses made by the student on the end of term questionnaire.

The study also considered the variation in the average length of $T$-units in individual students' journal entries in the interest of providing an additional case of $T$. unit use in an ESL context and exploring the relationship with writing quality as defined in research question 2. The average length in number of words was computed and then compared with the Jacobs profile scale quality assessment. Averages of T-unit length 
were assessed for entry types to determine if certain topics resulted in longer $T$-units, which might suggest a higher level of complexity (Stanton, 1993).

\section{Qualitative Analysis}

The overall quality of the entries was assessed according to the Jacobs writing proficiency profile (1981) which considers content, organization, vocabulary, language use and mechanics as stated in research question 2. Appendix D provides an example of the criteria used in determining the Jacobs score (1981). Although the resulting score is a quantifiable figure, the Jacobs scores were included as a qualitative measure since they were used to determine the relationship of the topic variable and the quality of writing produced in the resulting entries.

To insure consistency in assessing quality scores the researcher selected a scoring mechanism with which she was familiar and had previously used with consistency. In addition, the researcher scored the entries only after carefully reviewing the single rater training instructions included in the writing proficiency guide, Testing ESL Composition: A Practical Approach (Jacobs et al., 1981). After consistently scoring the writing samples included in the training guide within 5 points (the acceptable degree of variation) of the experienced raters' scores, the researcher felt confident in her ability to consistently assess the data. The entries were scored in a relatively short period of time, one week, and previously scored entries were reviewed before each scoring session. Finally, the researcher had a sample of 11 journal entries scored by a second rater and obtained an interrater reliability score of $91 \%$. For the purposes of this study, the expected margin of error for the Jacobs profile will be 6.27 , the average margin of error for one rater as documented in the scoring guide (Jacobs et al., 1981, p. 69).

To determine which topic type results in the highest quality entries for the entire group, the Jacobs profile scores were averaged according to topic type, resulting 
in a group, topic type Jacobs score. The Jacobs scores were also averaged for each entry, so each entry has a group Jacobs score as well.

Individual trends in students' journals were assessed in a similar manner except the scores were only averaged according to topic type. Individual entry scores were also compared to the student's own assessment of their journal entries as reported in the end of term questionnaire. In addition, trends noted in the individual qualitative analysis included: the failure to address the assigned topic and the types of topics chosen when no topic was assigned.

\section{Other Interaction}

Individual student responses to instructor comments were measured in frequency and in length, in terms of total token words. Other interaction, such as unprompted comments, questions, and other writing, was noted in the individual analysis of the students' journals in attempts to generalize about how students use their journals to communicate with the instructor.

\section{Questionnaires}

Results from the questionnaires were summarized in two ways. Common patterns of response among all students enrolled in the course were considered for questions one, two, three, six, seven, eight, and eleven. Individual responses were also analyzed and compared with the researcher's assessment of overall journal performance as well as particular entries.

The results of the research methodology detailed above are discussed in length in the following chapter. A discussion of the results is contained in Chapter V. The limitations of the research methods used in this study are covered in Chapter VI. 


\section{CHAPTER IV}

\section{RESULTS OF THE STUDY}

In this chapter, the results of the study for both group and individual journals are discussed. First, general findings for the group are discussed. As part of this discussion, the relationship between topic type and quantity of writing produced in terms of average number of words is examined. This is followed by an analysis of the relationship between the quality, according to the Jacobs profile (1981), and the assignment of topic. The group results conclude with a summary of the responses found in the end of term questionnaires.

Then, the variation of individual student journals is examined on a student by student basis. The relationship among topic types and quantity and quality of writing produced is again discussed. In addition, the relationship of T-unit length is compared to the Jacobs score quality analysis. The individual students' responses from the questionnaire are compared to the researcher's findings and individual attitudes toward journal keeping are reported when relevant. Also included in this section are excerpts from student journals and observations made by the researcher.

\section{GROUP RESULTS}

The following results are based upon a total of 144 journal entries generated over a period of eight weeks by ten students, six who had had previous journal keeping experience and four who had not. Missing journal entries are noted but were not included in the averages. The results are grouped according to the variable of topic 
TABLE III

GROUP AVERAGES FORTOPIC TYPES

TYPEA TOPICS

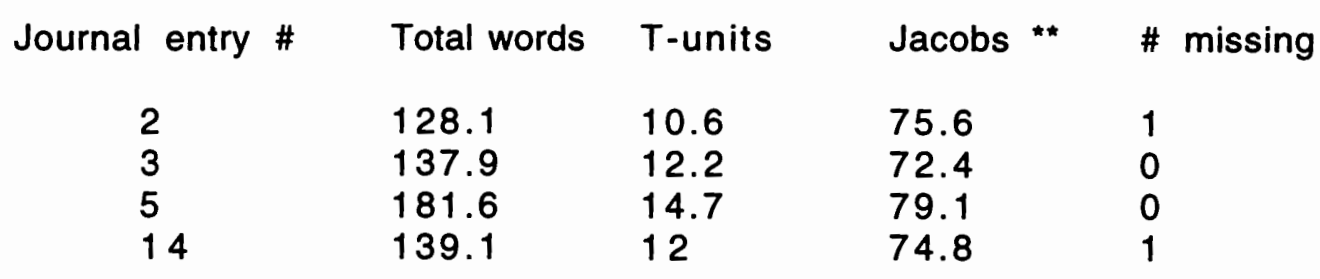

$\begin{array}{lllll}\text { Average } & 147.4 & 12.4 & 75.0 & .5\end{array}$

TYPE B TOPICS

\begin{tabular}{|c|c|c|c|c|}
\hline $\begin{array}{l}1 \\
7 \\
11 \\
16\end{array}$ & $\begin{array}{l}132.6 \\
148.2 \\
144.6 \\
160.9\end{array}$ & $\begin{array}{l}11.6 \\
12.5 \\
12.8 \\
14.9\end{array}$ & $\begin{array}{l}75 \\
74.5 \\
76.4 \\
78.9\end{array}$ & $\begin{array}{l}1 \\
0 \\
3 \\
2\end{array}$ \\
\hline \multirow[t]{2}{*}{ Average } & 146.6 & 13 & 76.1 & 1.5 \\
\hline & \multicolumn{4}{|c|}{ TYPE CTOPICS } \\
\hline $\begin{array}{l}6 \\
9 \\
10 \\
13 \\
15\end{array}$ & $\begin{array}{l}118.8 \\
146.7 \\
132.7 \\
151.3 \\
127.1\end{array}$ & $\begin{array}{l}9.9 \\
15.8 \\
12.2 \\
16.3 \\
10.3\end{array}$ & $\begin{array}{l}76.4 \\
77.7 \\
77 \\
76.3 \\
76.8\end{array}$ & $\begin{array}{l}0 \\
3 \\
1 \\
0 \\
2\end{array}$ \\
\hline Average & 133.6 & 12.9 & 76.8 & 1.2 \\
\hline
\end{tabular}

TYPED TOPICS

$\begin{array}{lllll}4 & 145.8 & 14.2 & 76.9 & 0 \\ 8 & 135.8 & 13.9 & 76.6 & 2 \\ 12 & 160.9 & 14.1 & 78.4 & 0\end{array}$

$\begin{array}{lllll}\text { Average } & 147.5 & 14.0 & 77.4 & .66\end{array}$

** expected margin of error $=6.27$ (Jacobs et al. , 1981, pp. 69) 
Type A topics focused on material presented in lectures or class discussions. Type B topics related information presented in class to the student's culture. Type C topics addressed personal or class activity related experiences. Type D topics consisted of no assigned topic or topic of the student's choice.

\section{Quantity of Writing}

Number of Words. The quantity of writing was calculated by averaging the number of words per entry for each student. Then, the group averages were calculated for each entry. For the group topic type averages all entries were grouped according to topic type and then were averaged again. The results show that although the average number of words per entry varied considerably, from 118.8 average words for entry \# 6 (Asking for Advice) to 181.6 average words for entry \# 5 (Divorce Your Opinion), the average number of word per topic type did not seem to greatly influence the average number of words for a given topic type. Figure 1 illustrates the slight variation in average word length. Type A topics averaged 147.4 words per entry, while topic B journal entries averaged 146.3 words per entry. Topic $D$ entries averaged a slightly higher 148.3 words per entry. The only noticeable variation was among type $C$ topics which averaged approximately 13 to 15 words less than the other topic types.

T-units. The average length in terms of the number of T-units per entry did not show a large degree of variation either (see Figure 2). Type D topics again produced the greatest average number of T-units, 14.1, but were only 1 to $1.6 \mathrm{~T}$-units longer than the other topic type averages. In terms of individual entry variation, the greatest level of difference was found among two entries of the same topic type. Entry \#6 (Asking for Advice) produced the fewest number of T-units, 9.9, while entry\# 9 (Communication Experience with an American) resulted in the greatest average number of T-units, 15.8. However, both were type C topics. 


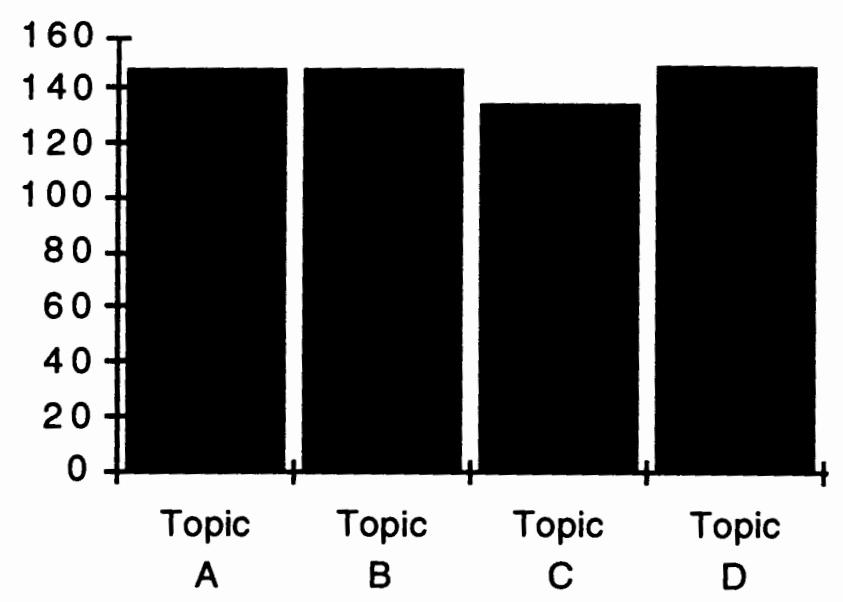

Figure 1. Group average of length in words according to topic

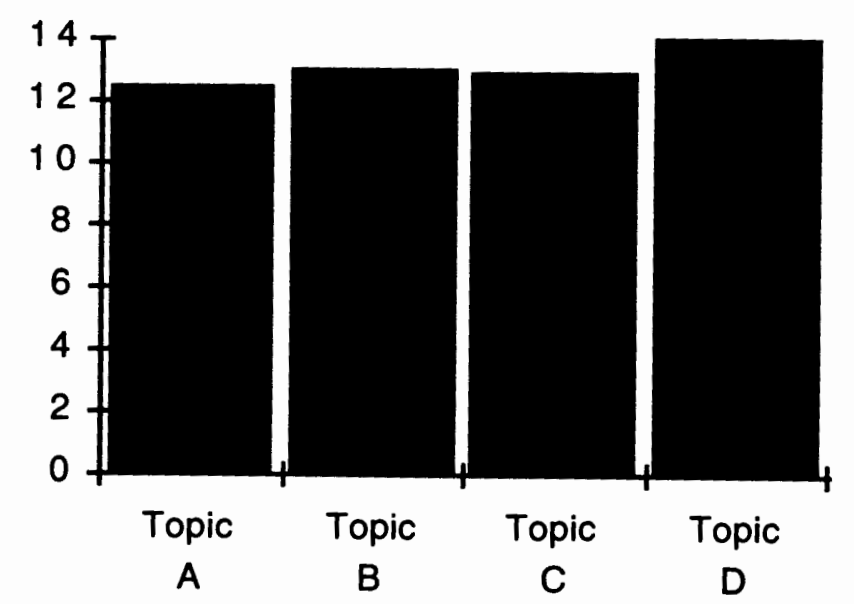

Figure 2. Group averages of length in T-units according to topic type.

\section{Writing Quality}

The quality of writing for each entry was assessed in terms of a Jacobs (1981) profile score. For each entry number, the corresponding scores for each student were 
averaged. Topic type average scores were calculated by adding all the scores of a certain entry type and dividing them by the number of entries. Again, missing entries were not included in the averages and entries that did not address the topic were rated slightly lower (up to ten points lower) in the content category, as addressing the topic is a descriptor in the content area assessment (see Appendix D).

The results demonstrate that, as a group, the Jacobs profile scores for type $D$ topics were only slightly higher than for the other topic types, and the total range of scores according to topic type was only 2.4 points. This is less than the expected margin of error (the standard measurement of error for one reader was typically only 6.27 points (Jacobs et al. 1981, p. 69)). Therefore, the difference in scores cannot be viewed as meaningful.

\section{Questionnaires}

The following results are based on the responses found in the eight questionnaires returned by the students participating in the study (for a copy of the questionnaire see Appendix A). The response rate of $80 \%$ was considered sufficient to draw general conclusions about student attitudes toward journal keeping. An acceptable level of honesty is assumed since students were repeatedly assured that their responses would not be viewed by the researcher until after grades were assigned and therefore would have no affect on their grade. Furthermore, the researcher strongly encouraged students to be honest since their responses may affect journal use in future classes.

Question one addressed the assignment of a topic versus student choice of topic. Figure 3 illustrates the following results. Out of eight responses, six preferred the teacher to give them a topic. One preferred to choose his own topic while one liked to choose his own topic sometimes. 


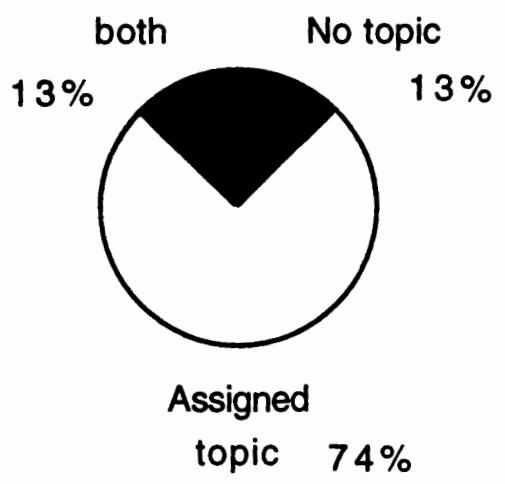

Figure 3. Student preferences of topic assignment.

When considering the type of topic preferred in question 2, two students stated that they preferred type B topics that involved relating their culture to a class discussion. Three students also stated that they liked to write on both type B topics and type $C$ topics, those relating to class or life experiences. Only one student clearly preferred writing on life experiences, solely type $C$ topics, while two students responded that they preferred type A topics, those that addressed class topics or lectures. These preferences are illustrated in Figure 4. The reasons for the stated preferences varied widely and are discussed in the section on individual journal results.

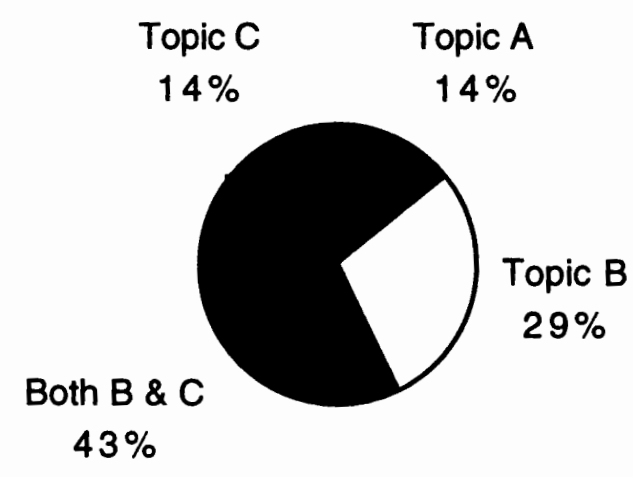

Figure 4. Student preference of topic type. 
Questions three, four, five addressed personal topic preferences and student quality evaluations and are discussed in the section on individual results.

When asked how much time they spent on journals, in question six, students generally responded that they spent half an hour to one hour and two students included that the time spent writing depended upon the topic.

The responses to question seven, which explored student reactions to instructor comments, show that all the students read the teacher's comments, but only two students stated that they ever responded to the teacher's comments. This is also consistent with the researcher's findings. Only three students (one of whom did not return the questionnaire) ever wrote any type of response back to the instructor. In terms of frequency, the response rate to instructor questions and comments was very low; only six responses resulted from the instructor's 65 direct questions. This resulted in a response rate of $9.2 \%$. No responses resulted from the 113 instructor comments. The number of words contained in these responses totaled 74 words plus one drawing. The reasons for the lack of response to instructor comments were various. Most stated that they thought about the teacher's comments or questions but didn't know they were supposed to answer or didn't know if the instructor would go back and read their answers.

Question eight asked students if they preferred journal writing to essay writing; six out of eight clearly preferred journal writing because it was easier and more enjoyable. Only one student preferred essay writing and one mentioned liking both since they were different kinds of writing.

Questions nine and ten addressed previous writing experience. Responses were incorporated into the individual subject profile in Chapter 3 and discussed in the Discussion of the Results in Chapter V. When asked if they would like to keep a journal next term, six out of eight responded in the affirmative, while two stated they would not. 
Finally, when asked what they liked or did not like about keeping journals, students did not offer very clear suggestions. One failed to respond, two affirmed their dislike for writing in general, two stated they liked keeping journals, two responded they liked writing and one welcomed the opportunity to express his ideas on class topics.

A complete discussion of these results is contained in Chapter V. The limitations of these findings, recommendations and suggestions for further study are included in Chapter VI. The following section deals with individual results for each student and observations made by the researcher.

\section{INDIVIDUAL RESULTS}

The purpose of reporting individual results is to illustrate the influence of topic on the quantity and quality of students' writing that is not apparent on a group level. The individual results provide an opportunity to compare the student's declared preference for certain topics and self evaluation and the researcher's quantitative and qualitative results. Furthermore, on an individual level, the quality of writing can be compared to measures such as average T-unit length.

The individual results are roughly ordered according to the total amount of writing produced over the term. The results of students who wrote less are addressed first and the results of students who wrote the most are considered toward the end of this section. They are not grouped according to nationality or gender since these factors did not seem to influence the amount they wrote, the quality of their writing or their topic preferences. All names given in the following section are pseudonyms and correspond with the student profiles presented in Chapter 3.

\section{Vassili}

Out of a total of 16 possible journal entries Vassili, a U.S. resident and full time 
student from the Ukraine, completed a total of ten. Appendix $E$ provides a summary of his individual results.

When considering topic type, he wrote more total words when no topic was assigned, type D topics, (see Figure 5). The average number of total T-units was also greatest for type D topics.

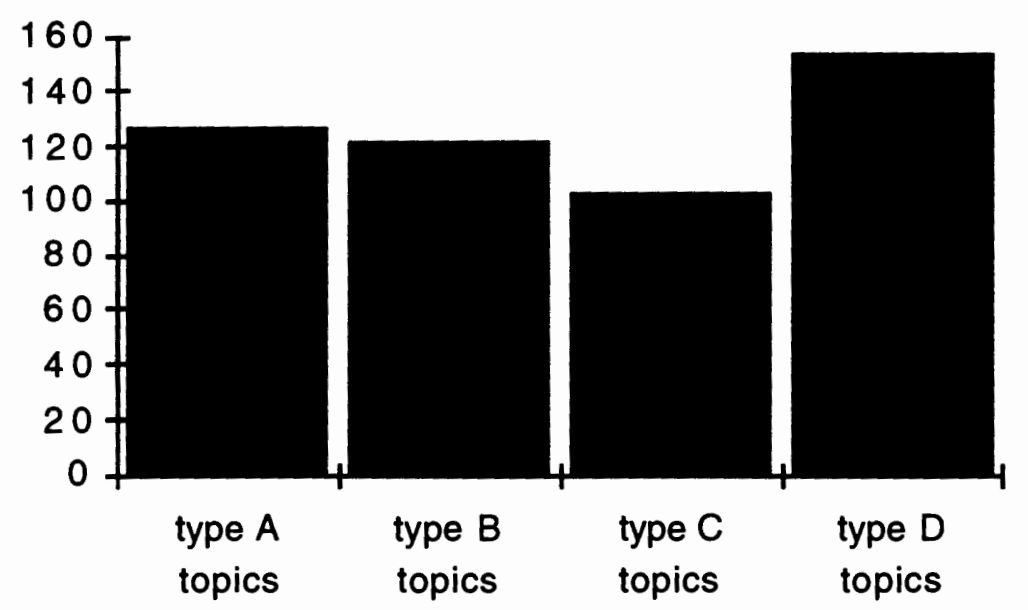

Figure 5. Length in words of Vassili's entries according to topic type.

His Jacobs score for type $D$ topics was also approximately five points higher than for all the other topic types. Although the margin of error for an individual rater may vary up to six points, it is worth mentioning that the average scores for all other topics is consistent, ranging only .5 points. In the case of length in terms of average number of words per T-unit, the results show that the entry with the longest T-units, \# 3 , received one of the lowest Jacobs quality scores, 61 points. This student did not return a questionnaire and hence has no responses that can be compared to the researcher's results.

When given a free choice Vassili tended to write about happenings in his life. One entry discussed a problem he had with parking his car at his apartment, while another described a trip to California. 
Inna

Inna, a full time student and U.S. resident from the Ukraine, wrote on 12 of the 16 possible journal assignments. Appendix $F$ summarizes the quantitative and qualitative results from her journal. When given a free choice of topic, her entries contained a higher average of words and number of T-units. Figure 6 illustrates the average amount of words written for each topic type.

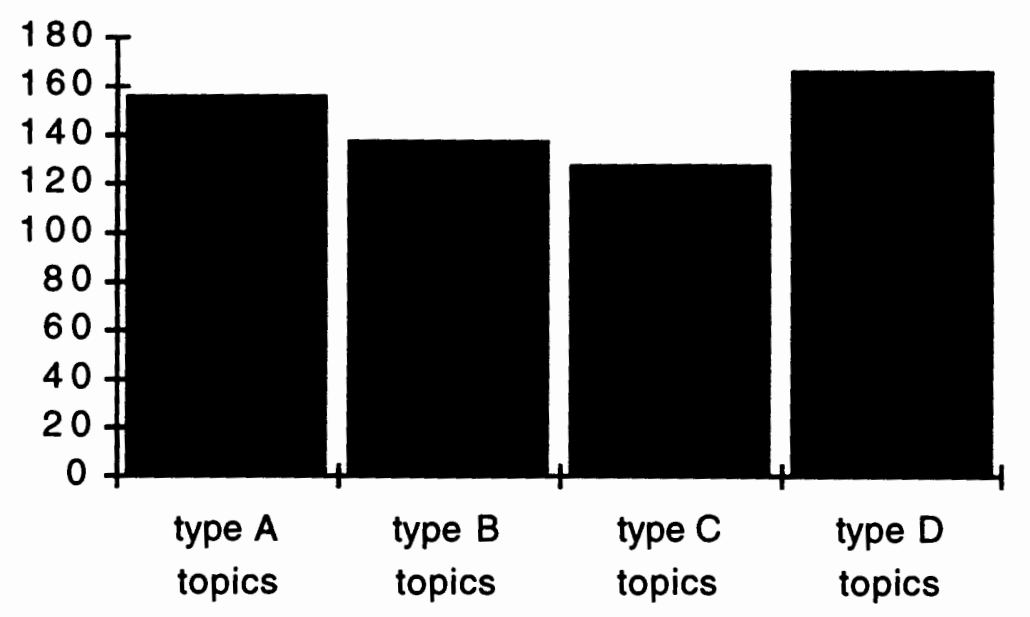

Figure 6. Length in words of Inna's entries according to topic.

The quality of writing as assessed by the Jacobs profile varied only slightly and seemed to have no relationship whatsoever with the T-unit length. Inna did not return the end of term questionnaire, so no comparisons can be made.

The researcher also made the following qualitative observations. When given a free choice Inna seemed to enjoy writing about her life in America and her family. In one entry she wrote about how much she likes Portland. The writing gave the researcher a better sense of her personality and her attitudes about living in the U.S. The following is an excerpt from one free choice entry:

I like Portland! Since I came here I have been wondering what a beautiful nature of portland is! The mountains, rivers, many parks and beautiful places always are attracted me to go outside on the weekend. I can't stay home if I have free time.

(student journal) 
In another free choice entry she wrote about her children and some of the problems of living in the U.S. The following is an excerpt from that entry:

I have two children, two sons... It is very interesting for me to watch how they are playing. . I miss my children very much when I am not at home . . I I want to spend with them most of may time, it is difficult for me doing something else...

(student journal)

Inna's journals revealed some of the reasons for her absences and failure to turn in assignments and helped the instructor/researcher understand her outside of the class situation.

Yoko

Yoko, a part time Japanese student, completed all 16 of her journal assignments. A summary of the quantitative and qualitative results are given in Appendix $G$. She wrote considerably more for type $B$ and $C$ topics; this is consistent with the preference of topic types stated in her questionnaire response. Figure 7 illustrates the average number of words written according to topic type. The average number of T-units was also slightly higher for type $B$ and $C$ topics, about 1.3 T-units longer than type $D$ topics and 2.8 Tunits longer than type A topics.

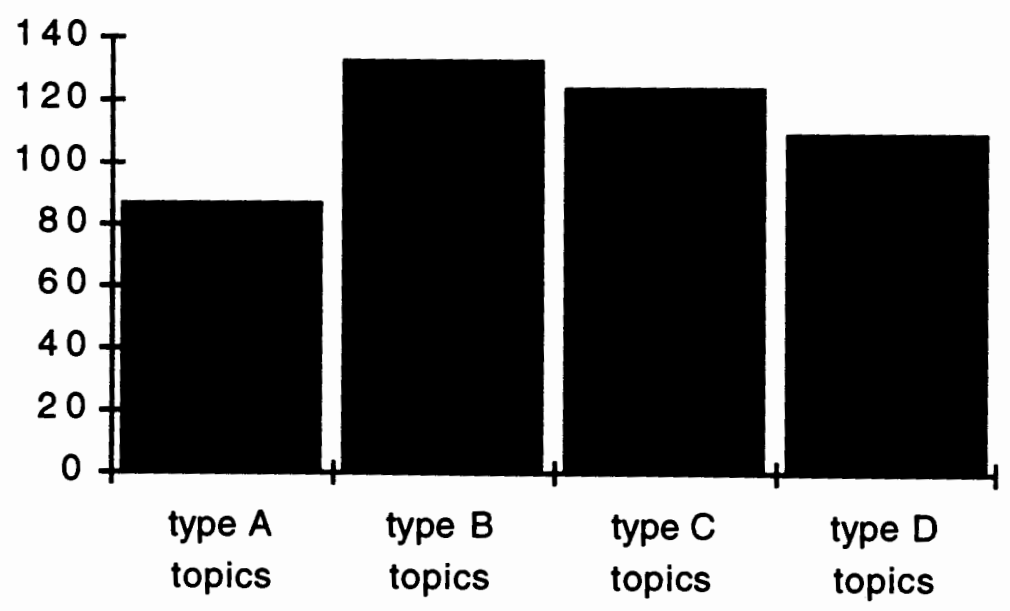

Figure 7. Length in words of Yoko's entries according to topic type. 
The relationship between the Jacobs profile and the topic type is of interest in Yoko's case. For type A topics the average Jacobs score was the lowest, 68 points. The Jacobs score for type $B$ topics was the highest, 77.5 points. These scores also correspond with the amount of words written for a topic type.

The reason Yoko gave for preference of topics is as follows: "Because both of these topics (relating my culture and my life/class experiences) are easy to write for me, and I need for long time for my choice." Yoko was not precise as to which entry she felt was best or enjoyed writing the most. She responded that text book entries, which included type A, B and C topics, were best and that she enjoyed writing on all type C topics.

When given a free choice Yoko tended to write on class topics. One entry summarized a lecture on U.S. immigration while the other discussed what qualities one looks for in a spouse. The latter topic stemmed from a small group discussion question after a presentation on dating in the U.S. The other entry, the first free choice of the term, discussed a personal experience, a trip back to Japan.

James

James, a full time student from Taiwan, wrote relatively little in his journal and was one of the few students who expressed a dislike for writing in general. James' results (see Appendix $\mathrm{H}$ ) indicate that he tended to write the most (in terms of both total words and number of T-units) when given a free choice. This corresponds with his response to the questionnaire that he preferred to choose his own topic. Figure 8 illustrates the consistency in the amount of writing produced for all topic types.

The average of the Jacobs' scores for type $D$ topics was also the highest but not considerably higher than type $C$ topics considering the margin of error. The average $T$ unit length did not correspond at all with the Jacobs quality assessments. In fact the entry with the shortest average T-unit length, \# 4, received the highest Jacobs' score. 


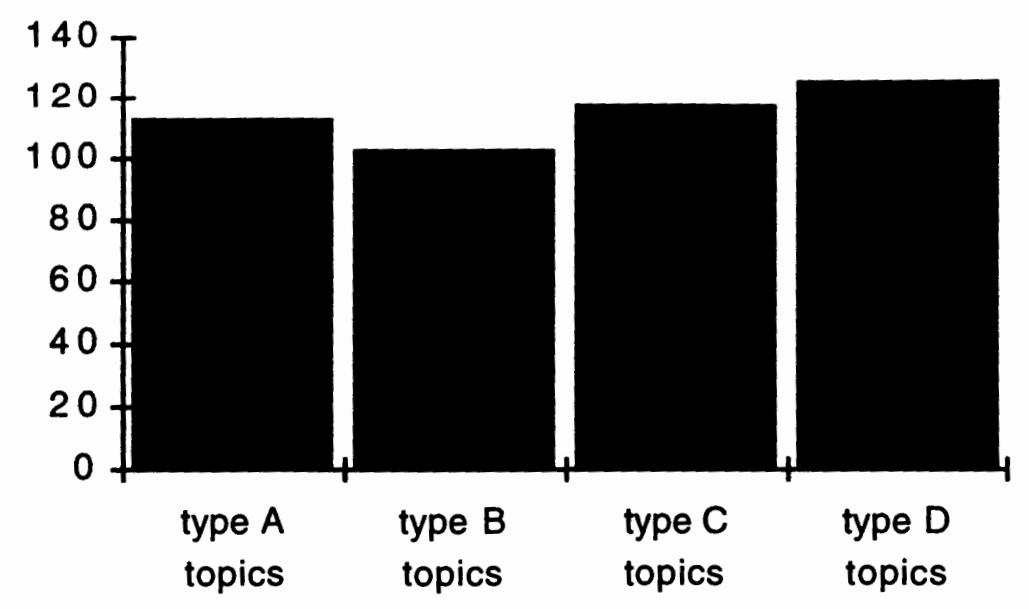

Figure 8. Length in words of James' entries according to topic type.

When given a free choice of topic James did not seem to focus on any particular subject. Sometimes he discussed his reasons for going back to school and how his impression of America has changed, but in one entry he addressed hopelessness in the U.S., a topic previously discussed in class. The information contained in one of the type D entries titled "Go Back to School" was particularly interesting. The following is an excerpt from that entry:

When I had worked for five years, I was tired. I was busy every day . . . I think I am a machine . . I could not have new idea. . I wanted to touch a new field in life. I did not want be a machine. Finally, I decided to go back to school, and chose America. I want to learn different knowledge and know different culture... .

(student journal)

Reading such entries provides a better understanding of the student's motivation and goals in learning English as well as a forum for personal communication which may not occur in class. Nonetheless, James stated that he did not like writing and would not like to keep a journal in the future. 
llena

llena, a full time student from Taiwan, although very vocal in class wrote less than many of the other students. The results, presented in Appendix 1, for llena indicate that she wrote an average of ten words more for Type A topics than type B topics and approximately 35 words more than type $C$ and $D$ topics. Figure 9 illustrates these findings. However, the average length in number of T-units written was slightly higher (.2 T-units) higher for type B topics. This does not exactly correspond with the preferences of topic type stated in the questionnaire, which included type B and Type C topics and not type $A$. The reason given for this preference was that she liked writing about the differences between her culture and American culture.

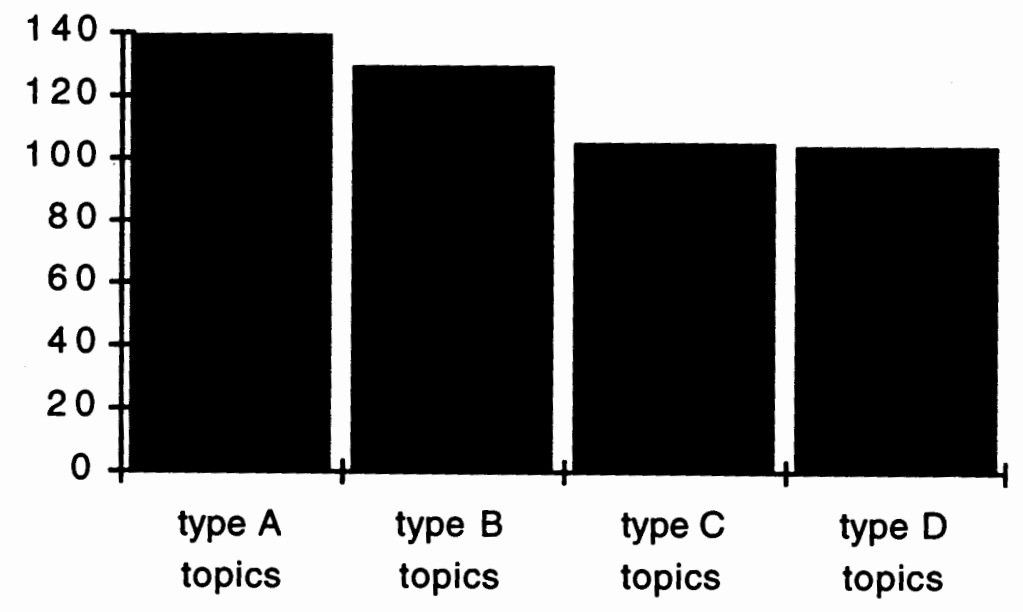

Figure 9. Length in words of llena's entries according to topic.

The quality assessment results of llena's journal were inconclusive. There was little variation of scores among topic type and the variations that exist among entries have no apparent relation to average T-unit length. The entry judged as best received the lowest Jacobs quality score, but this is because the student did not address the assigned topic, a lecture presented in class on Martin Luther King Jr. ; instead she wrote about how some people are shy and how others talk too much in class. This was a 
valuable insight, which normally wouldn't have resulted, had she addressed the assigned topic. Ilena also wrote one unprompted entry telling the instructor that she had found someone to interview for a class project and was one of the three students that responded to the instructor's comments.

\section{Thomas}

Thomas, a full time graduate student from Taiwan, was very consistent in his journal writing. He seemed to have a one page limit and indeed never wrote more than one page, even if he had to continue into the margin to finish an entry. Appendix $J$ summarizes the results of his journal entries. Not surprisingly, the results of the average total word length are fairly consistent from topic to topic. Figure 10 shows the regularity of his writing. Thomas tended to write slightly more for free choice topics, in total words, although he stated that he preferred having the teacher give him a topic, and preferred writing on type $A$ topics because he already had a reference and only had to modify the information a little bit. This is noteworthy since type $A$ topic entries resulted in the highest average number of T-units.

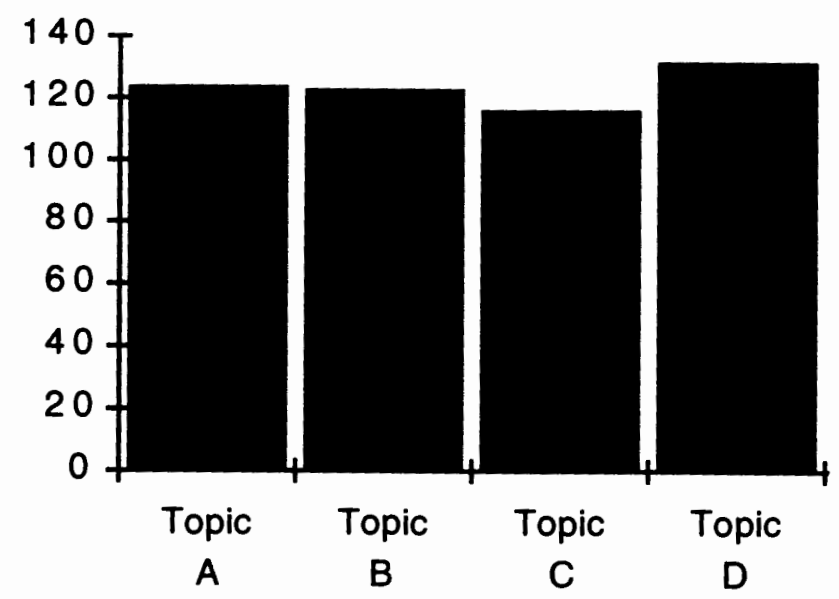

Figure 10. Length in words of Thomas' entries according to topic type. 
The qualitative results were inconclusive. The average Jacobs profile score did not vary in relationship to topic type. The student's own assessment of his writing corresponded somewhat with the researcher's quality evaluation. The entry that he felt was "best" was one of the "better" entries according to the Jacobs profile, although it did not receive the highest score. Thomas was one of the students who responded in the questionnaire that he did not like writing and would not like to keep a journal next quarter. However, his type D, free choice entries, often addressed language learning concerns and helped the instructor to focus on his needs. The following is an excerpt from entry \#6:

I have strange accent and different intonation in English ... . Sometimes people understand me roughly if I speak correct pattern and sentence structure, After these classes, I understand what is wrong gradually...

(student journal)

Finally, the one particularly insightful comment James made on the questionnaire was that he felt they should be corrected, so as to help him make better progress. The corrections he most likely refers to are grammar corrections since content was generally commented upon and confusing sentences often questioned, but not corrected for grammar.

\section{Hisayo}

As noted in the student profile Hisayo, a full time student from Japan was a particularly quiet student who rarely spoke in class. However, in her journal she was quite communicative and wrote more than many of the other students in the class. The results of her journal analysis are presented in Appendix K. She tended to write more total words on type $D$ topics in both total words and average number of T-units, as illustrated by Figure 11 . 


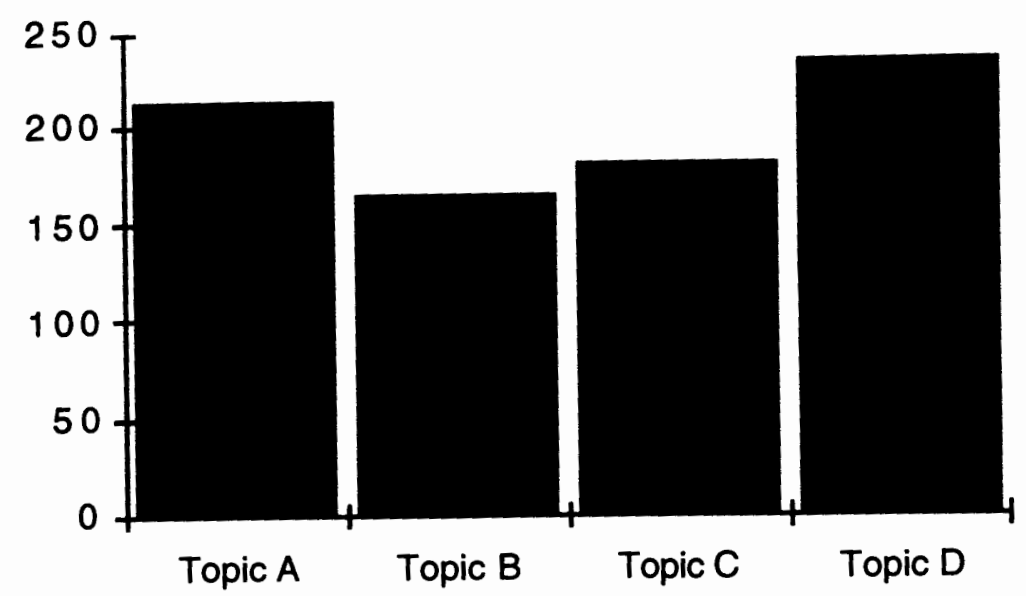

Figure 11. Length in words of Hisayo's entries according to topic type.

Hisayo's preference of topic was unclear from her questionnaire response. Although she stated that she preferred the teacher to give her a topic, when asked to specify which type of topic she responded that she liked "my choice and my experiences and relating to my culture" because they were easy to write. Such a preference includes Type B, C and D topics.

Although she stated a preference for type B topics, those that related class discussions to the student's culture, she wrote very little them and even concluded one entry on immigration with the following comment: "I never think about immigration trends in my country so it is too hard to think about this for me." Furthermore, she wrote far more on type A topics than on type B topics, although she didn't mention type A topics in her preferences.

The quality assessment again was not interesting as the difference in average scores is approximately the same as the margin of interrater error. Her "best" entry did not correspond with the evaluation of the researcher nor did her favorite entry.

When given a free choice of topic, Hisayo once wrote about her family, once about her friend and once discussed homeless people, a topic discussed in class. In this entry, 
she freely expressed the change in her attitude toward homeless people which resulted. from a study of homeless people as individuals and a class discussion. Although, this was the unstated goal of the unit it was rewarding to the instructor to have a student articulate this new perspective on the problem of homelessness.

\section{François}

François, a graduate student from West Africa, was the most skilled writer of the group and his journal entries reflected this. However, he was not the student who wrote the most. (The results of François' journal are summarized in Appendix $L$ ) in considering the length of the entries according to topic type, Figure 12 shows that François wrote the most on type A topics. This was for both the average of total words and the number of T-units. This is consistent with his stated preference for assigned, type A topics. Also, François was the only student that stated a preference for essay writing over journal writing. Type $A$ topics tend to be more abstract and relate less to the student's life and could be considered more like essay topics.

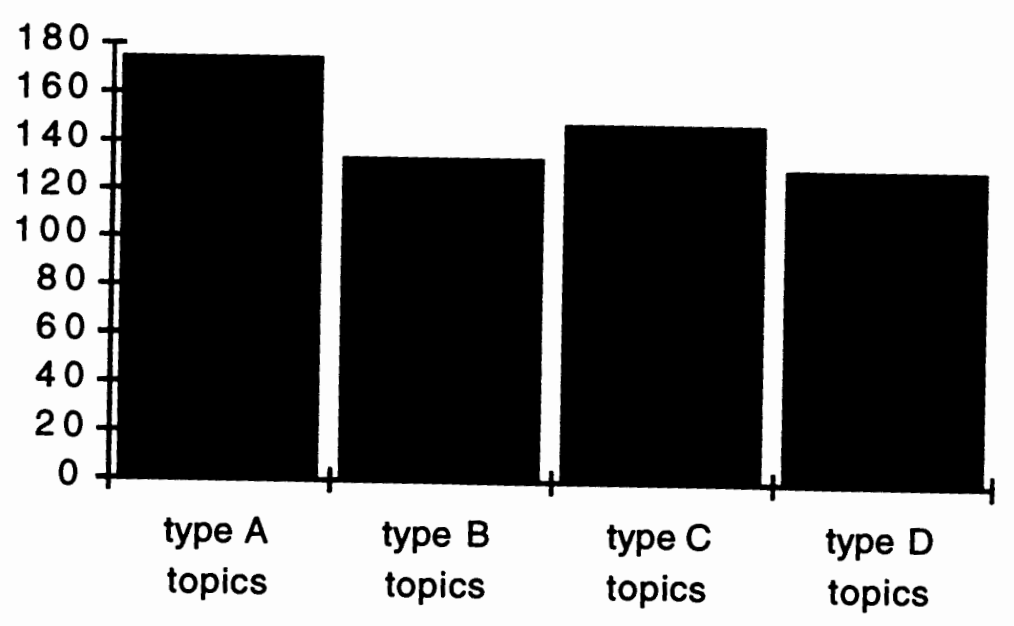

Figure 12. Length in words of François' entries according to topic type.

When considering the quality of entries according to topic, there was no measurable difference. Furthermore, the T-unit length in terms of average number of 
words did not have any relationship to the quality assessments either. However, the student's assessment of the "best" and "favorite" entries did correspond with the researcher's quality scores. In these two and many other of his entries, François clearly expressed his opinions and also mentioned that he enjoyed doing so in his response to the questionnaire. The following is an excerpt from an entry on divorce, a type $A$ topic:

Divorce is a tragic social event. I have never understood people who get divorce because I think they may be selfish and irresponsible. Particularly when they have children. Having said that, divorce is a result of many crazy decisions made by people who generally had chosen their partners on the basis of some subjectives trifles ...

(student journal)

The excerpt illustrates François' willingness to express his opinions and engage with an abstract topic.

\section{Danny}

Danny, an Indonesian male, was one of the only full time students who truly seemed to enjoy writing in his journal. He frequently wrote more than 200 words in an entry. The results of Danny's journal writing are summarized in Appendix M. Although Danny wrote a lot on all topics, he wrote the most when given a free choice as illustrated by Figure 13.

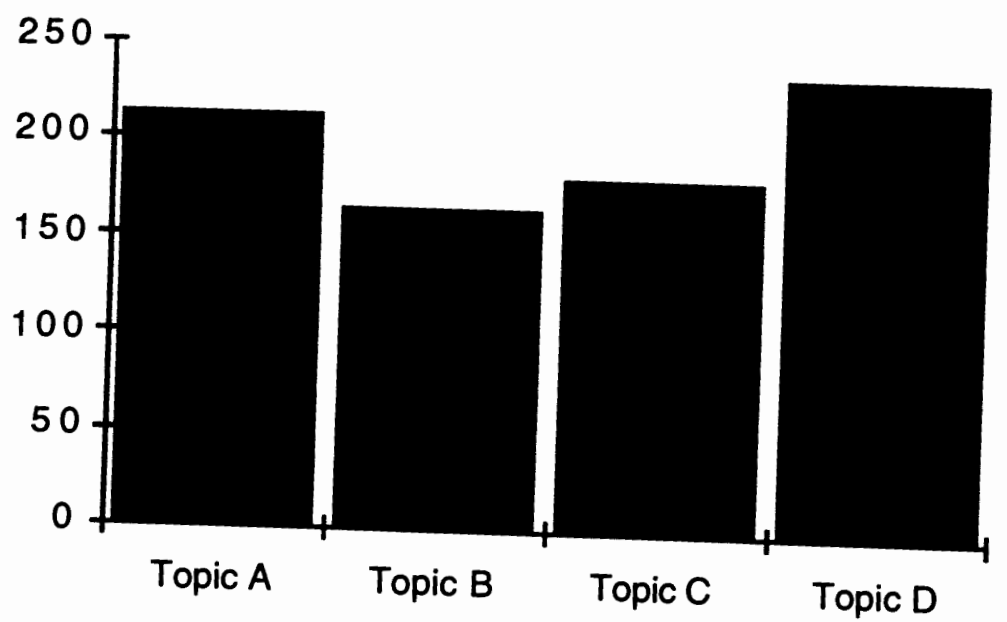

Figure 13. Length in words of Danny's entries according to topic type. 
This is somewhat consistent with his questionnaire response, that stated he liked both teacher assigned topics and free choice topics but admitted that sometimes it was difficult to think of his own topic. In addition, he voiced a strong interest in journal writing indicating that students who do enjoy writing may generally tend to write more.

When considering the quality of Danny's journal writing, the Jacobs score did not differ much among topic types, nor did the average length of T-units seem to relate to the quality assessments made by the researcher. When asked which entry he thought was the "best" and which one was his favorite, Danny felt that entry \# 5 fit both these descriptions. However, that entry received a relatively low quality score from the researcher, who rated one of his free choice entries the highest.

When given a free choice, Danny wrote about personal life experiences, in particular trips outside of Portland that involved doing something new or different. The following is an excerpt from a free choice entry that recounted a skiing adventure:

When I put the ski shoes on I begun to think what I would do with this heavy hard things on my leg. I could not walk because the shoes were so strange to me ... but after I had been falling down all over the snow I could control the ski and I knew how to sking!

(student journal)

Danny seemed to like to share his experiences and was one of the few students who wrote direct questions to the instructor as separate entries. Danny's willingness to express his learning experience and engage in a topic of his own choice is addressed in Chapter V, Discussion of Results.

Nike

Niko, a part time Japanese student, put an enormous amount of energy into her journal often including charts and illustrations that were beyond teacher expectations The quantitative and qualitative results of her journal are summarized in Appendix $\mathrm{N}$. Without question, she wrote more, approximately 100 more words, and T-units on type 
B topics than on type $C$ or type A topics. This dramatic difference is illustrated by Figure 14. The difference in amount of average words written on a topic also corresponds with her declared preference of topic type. She stated that she liked relating her culture to a class topic, and that this was fun for her.

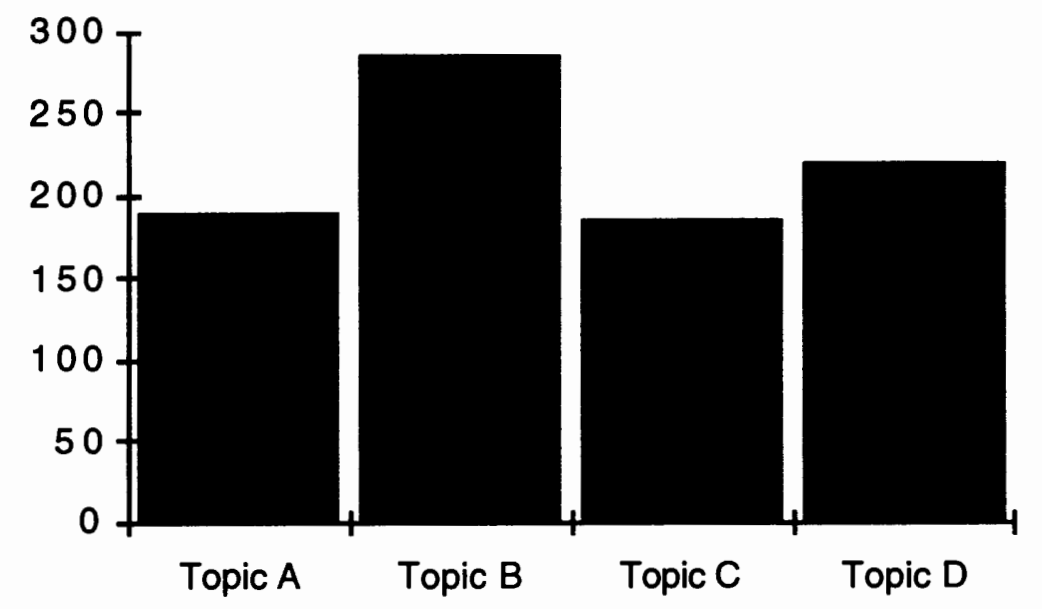

Figure 14. Length in words of Niko's entries according to topic type

The qualitative results of Niko's journal are not as informative. The Jacobs scores did not vary greatly from topic to topic although $A, C$ and $D$ topics were consistently five to six points lower than type B topics. Her assessment of quality was consistent with the researcher's to some degree. One of the entries she indicated as the "best" did indeed receive the highest Jacobs score of the entire study, and the other received a higher than average score.

When given a free choice, type D topic, Niko wrote about recent life experiences: other students she had met and concerts she had attended. Niko was also one of the few students that responded to the instructor's comments, and wrote unprompted entries that usually addressed personal questions or concerns about class assignments. 
In considering the entire group, it can not be concluded that one type of topic resulted in longer entries. However, type $C$ topics, those relating to personal or class experiences resulted in considerably shorter entries in terms of average number of words, and Type D topics, no assigned topic or "free choice" entries resulted in a higher average number of T-units written. The quality assessments were inconclusive on the group level.

On the individual level, however, the length of entries varied considerably in relationship to topic type. Furthermore, in many cases the increase in length did correspond with the student's stated preference of topic. The quality assessments were again inconclusive for the most part, and T-unit length in terms of average number of words had no relationship to the researcher's quality assessment. When considering which entries were best, only three out of seven students' assessments corresponded with the researcher's quality scores. The results of these findings are discussed in the following chapter and the researcher's recommendations for journal use and study of journals are included in Chapter VI. 


\section{CHAPTER V}

\section{DISCUSSION OF THE RESULTS}

The main question guiding this research has been: In what way does the assignment of topic influence the quantity and quality of writing produced in adult ESL student journals? Two measures, quantity and quality of writing, may be seen as an indication of student interest in or preference for certain topic types.

Also explored, was student reaction to instructor comments and attitudes toward topic assignment and journal writing in general. All these issues are addressed from several perspectives: on a group level as well as an individual level, since each student's journal provides insights that would have been missed if the research had only been conducted on a group level. At this point it is appropriate to discuss the areas of research and the answers provided by results detailed in Chapter IV.

\section{RELATIONSHIP BETWEEN TOPIC ASSIGNMENT AND QUANTITY OF WRITING}

For the purposes of this study four topic types were used: type $A$ topics, which related to the class lectures and discussions, often eliciting an opinion or a demonstration of understanding; type B topics which encouraged students to relate the information presented in class to their own cultures; type $C$ topics, which related to personal or class experiences, often focusing on an out of class assignment such as group projects, interviews, etc. ; and type D topics, which indicated no topic assignment or "free choice". 
The quantity of writing in student journals was measured in two ways: total words and number of T-units per entry. The following section discusses the results for length in terms of total words, the most revealing measure used in the study.

\section{Total Number of Words}

In considering the average length of entries according to topic type, it was found that, on a group level, no individual topic type resulted in longer entries, in terms of the average total number of words. However, on the average, students wrote less on type $C$ topics, those that addressed class related or life experiences. This was unexpected since educational literature (see for example, Goodman, Bird \& Goodman, 1991; Peyton, 1990; Vanett \& Jurich, 1990b) suggests that students would benefit from being able to relate to their personal experiences. However, as adults, students may not have felt comfortable writing on personal experiences. Nonetheless, when given a free choice, type $D$ topic, many students actually wrote about their personal experiences. This tendency to write at least the same amount (if not more in individual cases) when no topic was assigned, supports Reyes' (1991) findings that free choice in topic may be beneficial in journal style writing.

When looking at students' journals on an individual level, there was a great deal of variation of the average length of entries in relationship to topic type. Figure 15 illustrates both the individual and group variations of length in words according to topic type. Two students wrote more on type A topics. One was François, an experienced writer, who stated a preference for essay writing. Perhaps the more abstract nature of type A entries was appealing to him and gave him an opportunity to voice his opinions in a clear argumentative fashion. The other student, llena, produced more writing on type A topics, but did not often address the topic assigned, and to a certain degree she developed type A topics in her own way often resulting in something that more resembled a free choice entry. Appendix O provides several examples of type A entries. 
Average number of words per entry

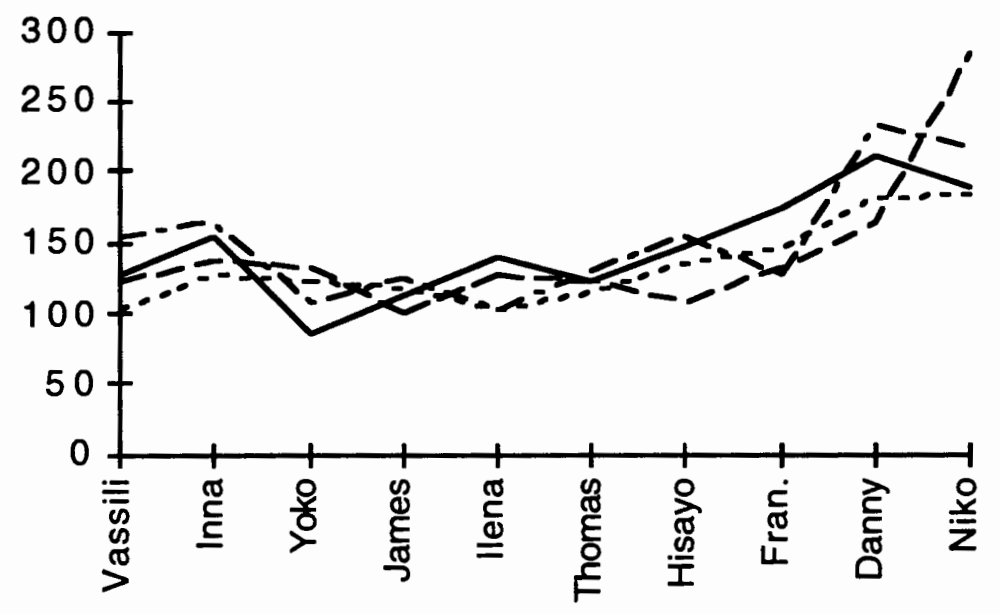

Type A topics

Type B topics - ----------

Type $C$ topics

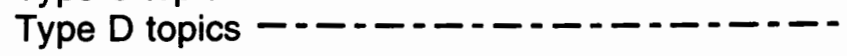

Figure 15. Individual variation according to topic type.

On an individual level, type B topics resulted in longer entries for only two students, both Japanese females. One of these was Niko, who wrote more than most students on all topic types and stated that she enjoyed writing in general, so perhaps topic type was not so much a factor as the detail in which she could develop the topic. For type $B$ entries of several of these students see Appendix $P$

Six out of ten wrote more on type topic D. Four of these students were male and two were female. However, two of the male students, both Taiwanese males, were fairly consistent in their writing and wrote only slightly more for type D topics. (For copies of type $D$ journal entries for several of the above students see Appendix Q). It should also be noted that on an individual level, type $D$ topics, in only one instance resulted in 
the shortest average entries. This was for François, the most advanced writer of the group, who stated a preference for a more formal style writing . He may have advanced beyond the level of expressive, personal narrative writing style. This is in accord with Freedman and Calfee (1984) who believe that as writers progress, they outgrow the personal narrative style and grow into more complex analytical writing styles.

Although type $\mathrm{C}$ topics (see Appendix R for examples) did not consistently result in the shortest entries for students, they never resulted in the longest entries for any of the students on an individual level. Furthermore, type D, free choice entries, were often longer than the assigned type $\mathrm{C}$ topics, although they often dealt with similar concerns. On an individual level this was especially true. For example, when assigned to write about a communication experience with an American, entry \# 9, Thomas wrote 115 words, but when given a free choice he wrote 153 words on communication problems he had encountered.

Similarly, Vassily wrote very little on type C topics, and generally failed to do them all together, but when given a free choice, he willingly shared his personal experiences. In one entry, \#8, he described a communication and cultural problem he had had with his neighbor over a parking place and in another free choice entry, he wrote about a trip with some fellow Ukrainians to California; he mentioned how nice it was to visit with old friends and feel at home and speak Russian. He revealed more about his feelings toward language in this entry than in any of the assigned entries. Hence, in some cases allowing the students to choose and develop their own topics may result in longer and more meaningful entries concerning personal experiences than when the instructor specifically assigns a personal topic.

\section{Average Number of T-units}

On the group level, students wrote slightly more T-units for type D topics and slightly fewer for type A topics, although the total difference was only 1.6 T-units and 
cannot be viewed as meaningful. The difference may best be accounted for by the type of writing each topic type encourages. Type A topics usually involve analysis or statement of an opinion, which may result in longer more complex constructions and therefore slightly fewer T-units. Yet, the discrepancy between the average topic type length measured in number of T-units and the total length in words may be of interest in further study especially when considering the ratio of function words (prepositions, auxiliary verbs, articles, conjunctions, transitions, etc.) to content words (nouns, verbs, adjectives, adverbs, and pronouns) (Stanton, 1993).

On an individual level, the average number of T-units for the most part tended to be a redundant measure for the length of entry. In only one case, did the type of measurement, average number of T-units written or average number of words change the results. Furthermore, the student in the case mentioned was very consistent in his journal writing and wrote nearly the same amount regardless of the topic type.

Nonetheless, as the results of the study have shown, students seem to have individual responses to different topic types as far as the quantity of writing is concerned. Some tend to always write the same amount; others, especially males, write more when given a free choice. Some students produce longer entries when they can relate the topic to their culture, and more advanced students seemed to find more to write when they can express their opinion on a certain topic. As demonstrated in the results section of this study, each topic type allows students to express themselves in different ways, which in turn aids the instructor in discovering their interests, concerns and individual needs, all of which make for more communicative interaction with the student. In conclusion, based on the results of this study, the researcher can advocate the assignment of various topic types in addition to the free choice of topic. 


\section{TOPIC ASSIGNMENT AND QUALITY OF WRITING}

On a group level the quality of writing did not vary enough to be considered interesting, given that the expected margin of error was 6.27 points. One reason for the lack of meaningful results was the effect of averaging the wide range of journal responses. While on an individual level many of the results concerning topic and quality were inconclusive, in some cases there did appear to be a relationship between topic and the quality Jacobs profile score. However, for the most part, the individual variations in the Jacobs profile scores also corresponded with the increased length (in terms of number of words) of entries, so it cannot be determined if the factor of importance is topic type or length of the entry since one of the criteria of the Jacobs profile is content, more specifically a thorough discussion of the topic. Hence, the quality score may be more directly related to the length rather than the topic type or vise versa. In general, it can be said that the quality of the writing, as judged by a proficiency scale, does not show much variation. This may be because the proficiency of the students stays consistent from entry to entry and may vary only slightly in relationship to topic type preference.

\section{Jacobs Profiles and T-unit Length}

The results from this segment of the study generally indicated that T-unit length had no relationship with the quality assessment and in some cases greater T-unit lengths were associated with lower Jacobs profile scores. In retrospect, the researcher believes that the quality and syntactic complexity of the entries may have been better assessed by using other measures. 


\section{WRITTEN REACTION TO TEACHER COMMENTS}

Although the journals in question were not true dialogue journals like those examined in several studies mentioned in the introduction and review of the literature, the response rate to instructor comments is an area of exploration of this study. The written reaction of students to instructor comments was very limited; only three students ever responded to comments. In terms of frequency, of 65 direct questions made by the instructor, only six resulted in some form of response from students, approximately a $9 \%$ response rate. In terms of length, these responses totaled 74 words plus one drawing, which resulted from a clarification request on the part of the instructor. This suggests that in some cases when words fail a student may resort to drawing in a sincere attempt to answer the instructor's question and that students really do use their journals to communicate.

The reasons reported for the surprisingly low rate of response frequency were varied. Several stated that they didn't realize they were supposed to answer, while others stated they didn't know how to respond or didn't understand the questions. One mentioned that he didn't know if the teacher would go back to read his answer, a reasonable consideration, given that the length of the journal entries frequently exceeded one page and journals were collected on a weekly basis. Hence, the instructor would have to turn back several pages to read the responses to her comments, in addition to reading the new entries. However, all of the students reported that they did read the instructor's comments and often thought about them, mentally answering the questions but not bothering to write answers.

This indicates that if instructors desire written responses they need to voice this concern in class and explicitly state that they do go back and read responses. Another possibility would be to use a true dialogue journal format where instructor comments are used to generate the next student entry. However, this type of format may be 
difficult to integrate into a class where journal assignments are used to verify listening comprehension or reactions to outside class activities and assignments, such as interviews, group projects etc.

One other qualitative result worthy of discussion is that although many of the students did not respond to the instructor's comments, three students used their journals on occasion for unprompted comments or questions. Two of those who did respond to instructor questions, also wrote unprompted entries, and the other student generally wrote long and personalized entries, suggesting that these students felt more comfortable in their written interaction with the instructor and were more likely to view the journal as a dialogue than as an assignment.

\section{STUDENT ATTITUDES}

An open ended, end of term questionnaire was used to explore student attitudes toward various aspects of journal keeping. The two issues that were of most interest to the researcher included topic assignment and future use of journals since they both have the greatest implication for future classroom use of journals. As an additional source of information to aid in classroom planning and implementation of journal use, the time spent on journal writing, attitudes toward journal keeping versus formal writing and perceived quality of journal entries were also issues addressed in the questionnaire.

\section{Topic Assignment and Type}

While the results indicate that on a group level students did not tend to write more on any particular topic type, in response to the end of term questionnaires students stated almost three to one that they preferred to have topics given to them by the instructor. In addition some students stated that finding their own topic was difficult or required more time. However, when a topic was assigned there seemed to be no clear preference of topic type except that type A topics, those that relate to class lectures or 
discussions, were generally less popular than type $B$ and $C$ topics, those that related class lectures or discussions to the students' respective cultures and those that addressed personal or class related experiences. Furthermore, the stated preferences generally corresponded on an individual basis with the length in average number of words and $\mathrm{T}$ units for a topic type. This indicated that word or T-unit length may indicate topic type preferences.

The findings also support the assumption that limited English proficiency students may find it easier to write on topics that draw on their cultural background or personal experiences since the only students that stated a preference for type A topics were the two students who were considered skilled writers.

When asked which journal entry they enjoyed writing the most, the answers were also varied. Some did not report clear answers or listed several entries from various topic types. Others did not differentiate between their "best" entry and favorite entry, which may indicate some confusion over the nature of the question. For those that did mention a separate entry that they especially enjoyed writing, the mentioned entry did correspond with their topic preference. This question was intended to check the students' stated preferences with a different measure. However, since the clear response rate was rather low, no conclusions can be made.

\section{Attitudes Toward Future Journal Use}

Of the eight students that returned the questionnaires, six stated that they would like to keep journals in the future. However, the two who stated they would not like to keep journals in the future stated that they did not like writing in general, but nonetheless, preferred journal writing to formal, essay writing. Although this cannot be seen as an overall endorsement for journal use in adult ESL classrooms, it does suggest that adults enjoy journal writing and do not seem to be bothered by the informal nature of journal writing. Furthermore, students seemed to take journal writing 
seriously and reported spending 30 minutes to one hour for each journal entry, depending upon the topic type.

The reasons supporting the use of journal writing and suggestions for the future differed. Several liked the informal nature of journals while others enjoyed the chance to write about their cultures or express their opinions about class topics. The variety of reasons for liking journals suggests that assigning a variety of topics is again a worthwhile consideration.

\section{Student Assessment of Quality}

As stated earlier, due to relatively high expected margin of error and the low level of variation, the Jacobs profiles were not successful in establishing a relationship between quality and topic type so the following results may also need to be viewed cautiously. In more than half the cases the students' assessment of quality did not correspond whatsoever with the researcher's assessment using the Jacobs profile. Of the three students whose quality assessments did correspond with the researcher's, two were considered skilled writers. This is interesting since it implies that skilled writers may be better able to evaluate their own writing or that they understand the evaluation criteria generally used in the Anglo/American academic systems and even in journal writing follow what they have discovered to be the normal conventions for writing (i.e. general organization patterns, use of supporting examples, transition words, tense consistency etc.).

\section{CONCLUSION}

"I like writing about my culture, it's fun!" , "I want to keep journals next term", "I hate writing", "It's better the teacher give me topic", "Sometimes I like to choose my own topic" - The diversity of responses to the end of term questionnaire reflect the wide range of opinions and preferences of the students themselves. 
Therefore, it is not surprising that when averaged together the results of their journal entries fail to show any group trends. Each student has his or her own topic preferences and approach to writing journal entries. This chapter has discussed the results of the study in a general way, to illustrate common patterns found in the journal entries and questionnaires. These insights hopefully provide a comprehensible view of topic assignment issues and student attitudes toward journal keeping. The implications for TESOL which have been partially addressed in this chapter are further discussed in the following and final chapter in addition to the limitations of the study and suggestions for further research. 


\section{CHAPTER VI}

\section{CONCLUSIONS AND RECOMMENDATIONS}

\section{TOPIC ASSIGNMENT AND JOURNAL KEEPING: A SUMMARY}

This study has attempted to establish a relationship among topic assignment and the quantity and quality of the resulting entries. In addition, student reactions to instructor comments and attitudes toward journal keeping have been explored. The data, journal entries from ten adult ESL speaking and listening students enrolled in a large west coast university and an end of term questionnaire, were collected over a period of ten weeks. The quantity of the entries was measured in terms of total words and total number of T-units. The quality of the entries was assessed according to the Jacobs profile (1981) which considers the following areas: content, organization, vocabulary, language use and mechanics.

It was found that, on a group level, assignment of four specified topic types (A. topics relating to class lectures and discussions, B. topics relating class discussions to the students' respective cultures, $C$. topics relating to class or personal experiences and D. no topic assignment) did not appear to have any relationship with either the quality or quantity of writing. However, on an individual level, topic assignment did seem to have an interesting relationship with the quantity of writing and in some cases, the quality as well.

Most students seemed to have a preference for a certain topic type that resulted in longer journal entries, but these preferred topic types varied widely from student to student. Therefore, when averaged together on the group level, the diversity found 
among individuals resulted in non significant findings when using a Chi square measure or only vague relationships when using descriptive statistics. This was contrary to the researcher's expectations. A review of TESOL literature had suggested that type B topics might have resulted in longer, higher quality entries since students could use the vocabulary presented in class discussions and draw on their own cultural background in writing their journal entries. However, this was not the case.

In considering the results from the inquiry into student reaction to teacher comments, the findings were much more enlightening. It was found that the response rate to instructor questions was only $9.2 \%$ and a total of 73 words and one drawing. Instructor comments did not generate any student response whatsoever. However, all students returning the questionnaire stated that they read instructor comments, indicating that they were interested in communicating with the instructor. The low rate of response to instructor questions may have been due in part to a lack of communication. To avoid influencing the results of the study, the instructor never clearly stated that she wanted the students to answer the questions nor did she state that she would go back and read the students' answers.

When considering the results from the end of term questionnaire, $74 \%$ of the students stated that they preferred the instructor to give them a topic, yet $60 \%$ actually wrote more when given a free choice of topic. When asked what assigned topic they liked the most, students stated a variety of preferences which roughly corresponded with an increase in length of entries.

All students seemed to take their journal writing seriously, spending from one half to one hour on an entry. Furthermore they seemed to enjoy journal writing as a form of written expression and $80 \%$ stated that they would like to keep a journal next term. Interestingly, the two students who stated they would not like to keep a journal next term, expressed a strong dislike for writing in general, but preferred journal 
writing to formal writing. The one student who stated a preference for formal writing was considered the most advanced writer and a skilled L1 writer. This is consistent with Freedman and Calfee's (1984) belief that as writers become more advanced they may "out grow" the narrative style and favor less personal, analytical or persuasive writing tasks. Therefore, when using a journal format with advanced level writers this preference for formal writing should be a consideration in topic assignment.

\section{LIMITATIONS AND DIFFICULTIES}

As a classroom, case study, this project faced several difficulties and did not progress as well as planned. The assignment of topics had to correspond with class activities, so the topic types were not as evenly distributed as desired, and in some cases the interest level or liveliness of discussions may have influenced students' writing habits more than the topic types themselves. This factor was not accounted for in the design of the study. Furthermore, students did not always complete the journal assignments which were to serve as data or on occasion did not write on the assigned topic. Two of the participants did not return the questionnaire and even those who did were not always clear in their responses. These difficulties as well as sample size and the questionnaire format used limit the implications of the study.

\section{Sample Size and Data Collection}

Although designed as a case study, some of the major limiting factors of this research include the sample size, number of subjects generating data, and the time over which the data were collected. Broader generalizations could be made if more student journals had been included in the data. However at the time of the data collection, ten students were thought to be sufficient representation of an average adult academic ESL class. In addition, it is not clear if more data would lead to more important differences or only closer averages. Another related problem is that all the data were generated in 
one classroom and the influence of the instructor is difficult to account for or control. Students may write more or less, respond more or less frequently to questions depending on their attitude toward the class, the instructor and the perceived benefit of the task. Data collected under one instructor may be completely different from data collected under another.

\section{Qualitative Evaluation}

In evaluating the quality of writing, there were also some difficulties. The measure chosen to assess quality, the Jacobs profile (1981), did not prove to be adaptable to the researcher's purpose. In most instances, the margin of error surpassed any differences in scores, resulting in non informative data. This is partially because the Jacobs profile was designed to measure general writing proficiency, not fine degrees of variation among different samples of one writer's work. Nonetheless, a writing proficiency scale, such as the Jacobs profile, was far more consistent in evaluating writing samples than the T-unit length measure, which proved to have no relationship with the quality assessments made by the researcher.

\section{Questionnaires}

Another limitation was the questionnaire procedure used. Rather than conduct ten personal interviews with a third party, it was believed by the researcher that more meaningful insights could be obtained by using an open ended questionnaire format. All students in the class were given the questionnaire to complete at home, but only the responses of those participating in the study were included in the results. This was an attempt to ensure that the conclusions drawn by the researcher were indeed related to the journal data collected, and participants of the study were identified by their hand writing, of which the researcher had numerous samples. This limits student input to the ten students participating in the study. 
In addition, the open ended nature of the questionnaire often led to ambiguous answers, as in the case of the students who stated preferring two topic types or one student who stated that all journal assignments from the book, which included type A, B and $\mathrm{C}$ topics, were the "best". A format that forced a clear choice perhaps would have worked better. It is not believed that the halo effect, or an attempt to please the researcher was a major consideration, since the students were not aware of their selection in the study. Furthermore, several students were very open in expressing their opinions, especially their general dislike for writing.

\section{RECOMMENDATIONS FOR FUTURE JOURNAL USE}

From the results of this study and the many other studies and project descriptions (see for example: Peyton, 1990; Dolly, 1990; Bell, 1984; Vanett \& Jurich 1990 a \& b), the researcher recommends journal use in general as a format for personalized communication with students, as journal format can be adapted to almost any skill area or proficiency level. Furthermore, as the questionnaires indicated, adult ESL students do seem to enjoy the journal format and the majority of students responded that they would like to keep journals in the future. Specific recommendations concerning assignment of topic type and strategies for instructor responses are addressed in detail in the following sections.

\section{Topic Assignment}

In the case of topic assignment, it was found that preferences among students varied widely and that no single topic type resulted in longer or higher quality entries for the entire group. Instead, it seemed that students had individual preferences for topic types, and the reasons for preferences may have been one or a combination of any of the following factors: like or dislike for writing, personality, ethnicity, gender or writing ability. Some students simply do not like writing regardless of the topic. Some 
students may feel more comfortable sharing their journals with the instructor or may feel the need to communicate while others may not. The ethnic background of the student may play a role as students from an oral tradition may feel more comfortable with the conversational format of journals, while others may not feel it is appropriate to speak/write freely to the instructor. The results of this study indicated that males tended to write more when given a free choice so gender may be a consideration as well. Writing ability may influence a topic preference as well since a more advanced writer may not be challenged by narrative or free choice writing assignments. Therefore, to suit the diversity generally found in adult ESL programs, the assignment of a variety of topic types is recommended, including no topic assignment or free choice entries. A variety of topic types can help each student find their area of interest or what Bell termed as a personal "genre" (1984, p. 2). More analytical topics may be favored by advanced writers; lower level students may feel more comfortable in discussing their own culture and personal experiences, while others, especially male students, may benefit from the autonomy of choosing their own topics.

\section{Instructor Question and Comment Strategies}

Although the researcher was not using a specific dialogue journal format, where students write short daily entries as a conversation with the instructor, the response rate to instructor questions was surprisingly low. It is suggested that if instructors desire responses to their questions or comments, they clearly voice this desire in class several times, since many of the students in the study indicated that although they always read the instructor's comments and questions, they did not realize the instructor really wanted them to respond or would read their responses.

The low response rate may have been partially due to the length of the entries, which often exceeded one page and the frequency of journal assignments. This may have led students to believe that once an entry was written and read by the instructor, that it 
was finished and that their attention should be focused on a new entry. Therefore, a second recommendation would include giving students the specific task of responding to one of the instructor's questions or comments, perhaps as a follow up journal assignment after journals were returned. Another option would include using a true dialogue format where instructor comments are used to generate individualized journal assignments. However, if this is the case, journals must be collected and read after every entry.

\section{SUGGESTIONS FOR FURTHER RESEARCH WTTH ESL JOURNALS}

ESL journals provide a rich source of data; not only do students express themselves in an informal, communicative manner, but they share information about their own cultures, language learning experiences and perceptions of the surrounding American culture. However, this type of data is difficult to quantify. Therefore, many researchers have looked at specific features such as T-unit length, quality of writing, content words versus function words, topic assignment etc. (see for example: Bell, 1984; Peyton, Stanton, Richardson \& Wolfram, 1990; Shuy, 1990; Stanton, 1990; Reyes, 1991) or written project descriptions. All of these areas are worthy of further exploration since the results may vary depending on the setting.

However, in doing the research for this project, the most interesting and informative aspect of journals was the content or information found in the entries themselves, the opinions, experiences, cultural notes and personality revealed to some degree by each student. In conclusion, the researcher recommends that future research with journals be qualitative in nature, focusing on the content of journals rather than the number of words or other quantifiable measures. Journals could perhaps be incorporated into ethnographies or introspective studies on language and culture learning. Finally, the influence of journals on instructor rapport with students would 
be of great interest since, in a large class, journals are often the sole means of personal communication between the instructor and students. Just how important this contact is, and how it may influence an instructor's relationship with a class is an issue worthy of investigation. 


\section{REFERENCES}

Anderson, R. C. \& Pearson, D. P. (1984). A schema-theoretic view of basic processes in research comprehension. In D.P. Pearson (Ed) Handbook of reading research. (pp. 225-291). New York: Longman.

Bell, A. (1984). Tales from the homeland: Developing the language experience approach. Tacoma, WA: Tacoma Community House.

Bernhart, E. B. (1984). Toward an infromation processing perspective in foreign language learning. Modern Language Journal, 68(3). 322-321.

Bloom, B. S. (Ed). (1956). Taxonomy of educational objectives handbook I: Cognitive domain. New York: David Mc Kay.

Brock, C. (1986). The effects of referential questions on English as a Second Language classroon discourse. IESOL Quarterly, 20(1). 47-59.

Brown, J. \& Baily, K. (1984). A categorical instrument for scoring second language writing skills. Lanquage Learning, 34(4). 21-43.

Cumming, A. (1989). Writing expertise and second language proficiency. Language. Learning, 39(1). 81-142.

Dolly, M. (1990). Integrating ESL reading and writing through authentic discourse. Journal of Reading. 33(5). 360-365.

Flower, L. \& Hayes, J. (1980). Cognition and discovery: Defining a rhetorical problem. College Composition. 31(1). 211-32.

Freedman, S. W. \& Calfee, R. C. (1984). Understanding and comprehending. Written Communication 1(14) 459-490.

Gaies, S. (1980). T-unit analysis in second language research: Applications, problems and limitations. TESOL Quarterly 14(1) 53-60.

Gipps, C . \& Ewen, E . (1974). Scoring work in English as a second language: the use of the T-unit. Educational Research, 16(1). 121-125.

Goodman, K. S., Bird, L. B., and Goodman, Y. (Eds.). (1991). The whole language catalogue. Santa Rosa, CA: American School.

Greenberg, K. (1985). Development and validation of the TOEFL writing test, IESOL Quarterly, 20(3). 531-544. 
Hansen-Strain, L. (1989). Orality/literacy and group differenced in second language learning. Language Learning. 39(4). 469-496.

Hunt, K. (1970). Syntactic maturity in school children and adults. Monographs of the society for research in child development (serial No. 134). Chicago, IL: University of Chicago Press.

Jacobs, H., Zinkgraf, S., Wormuth, D., Hartfiel, V. \& Hughey, J. (1981). Testing_ESL composition: a practical approach. Rowley, MA: Newbury House.

Johnson, P. (1982). Effects of comprehension on building background knowledge. IESOL Quarterly, 16(4). 503-516.

Kobayashi, H. \& Rinnert, C. (1992). Effects of first language on second language writing: Translation vs. direct composition. Language Learning, 42(2). 182215.

Krashen, S. (1982). Principles and practice in second language learning. Oxford:Pergamon.

Larsen Freeman, D. \& Strom, V. (1977). Language acquisition index development. Language Learning, 27(1). 123-134.

Lay, N. (1990). Composing process of adult ESL learners: A case study. TESOL Quarterly, 16(3). 406-407.

Lucas, T. (1988). Beyond language "and" culture: Individual variation in students" engagement with a written genre. Paper presented at the 22nd Annual meeting of Teachers of English to Speakers of Other Languages, (Chicago, IL, March 8$13,1988)$.

Moffet, J. (1968). Teaching the universe of discourse. Boston MA: Houghton-Mifflin Co.

Nemoianu, A. (1992). Looking for a focus: Transformations in journal entries Paper presented at the 43rd Annual Meeting of the Conference on College Composition and Communication (Cincinnati, $\mathrm{OH}$, March 19-21, 1992).

Ney, J. W. (1966). Review of grammatical structures written at third grade levels. Language Learning, 16(2). 230-235.

Perkins, K. (1980). Using objective methods of attained writing profiency to discriminate among holistic methods. TESOL Quarterly, 14(1). 61-69.

Peyton, J. (1990). Dialogue journal writing and the acquisition of English grammatical morphology. In J. Peyton (Ed), Students and teachers writing together. (pp. 65-97). Alexandria, VA: T.E.S.O.L., Inc. 
Peyton, J. \& Seyoum, M. (1988). The effect of teacher strategies on students' interactive writing: The case of dialogue journals. Los Angeles, CA: Center for Language Education and Research.

Peyton, J., Stanton, J., Richardson, G., Wolfram, W. (1990). The infulence of written task on ESL students' written production. Research in the Teaching of English, 24(2). 149-169.

Piaget, J. (1954). The construction of reality in the child. New York: Basic Books.

Raimes, A. (1985). What unskilled ESL students do as they write: A classroom study of composing. TESOL Quarterly, 19(2). 229-258.

Raimes, A. (1987). Language profiency, writing ability and composing strategiess: A study of ESL college learners. Language Learning, 37(3). 439-468.

Reid, J. \& O'Brien, M. (1981). The application of holistic grading in an ESL writing program. Paper presented at the 15th Annual TESOL convention (Detroit, MI March 1981).

Reyes, M. (1991). A process approach to literacy using dialogue journals and literature logs with second language learners. Research in the Teaching of English, 25(3). 291-313.

Schwartz, S. (1989). Using journal writing in the basic speech course. Paper presented at the 80th Annual Meeting of the Eastern Communication Association (Ocean City, MD, May 3-7, 1989).

Shuy, R. W. (1993). Using language functions to discover a teacher's implicit theory of communication with students. In J. Peyton and J. Stanton (Eds.) Dialogue journals in the multilingual classroom: Building language fluency and writing skills through written interaction. (pp. 127-154). Norwood, NJ: Ablex Publishing Corporation.

Spack, R. (1984). Invention Strategies and the college ESL compostion student. TESOL Quarterly, 18(4). 649-670.

Stanton, J. (1993). Dialogue journals as a means of assistiong written language acquisition. In J. Peyton and J. Stanton (Eds.) Dialogue journals in the multilingual classroom: Building language fluency and writing skills through written interaction. (pp. 103-126). Norwood, NJ: Ablex Publishing Corporation.

Sweigart, W. (1991). Classroom talk, knowledge development and writing. Research in Teaching English, 25(4), 469-496.

Tedick, D. (1990). ESL writing assessment: Subject matter knowledge and its impact on performance. English for Specific Purposes. 9(1). 123-143. 
Vanett, L. \& Jurich, D. (1990a). The missing link: Connection journal writing to academic writing. In J. Peyton (Ed), Students and teachers writing together. (pp. 65-97). Alexandria, VA: T.E.S.O.L. , Inc.

Vanett, L. \& Jurich, D. (1990b). A context for collaboration: Teachers and students writing together. In J. Peyton (Ed), Students and teachers writing together (pp. 21-34). Alexandria, VA: T.E.S.O.L., Inc.

Vann, R. J. (1978). A study of the oral and written English of adult Arabic speakers. Unpublished Ph. D. Dissertation, Indiana University.

Vygotsky, L. S. (1978). Mind in society: The development of higher psychological processes. M. Cole, V. John-Steiner, S. Scribner \& E. Souberman (Eds. \& Trans.) Cambridge, MA: Harvard University Press.

Vygotsky, L. S. (1962). Thought and language. Cambridge, MA: MIT Press.

Winfield, F. E. \& Barnes-Felfeli. P. (1982). The effects of familiar and unfamiliar culture context on foreign language composition. Modern Language Journal. 66(3). 373-378.

Zamel. V. (1982). Writing: the process of discovering meaning. IESOL Quarterly, 16(2). 195-209.

Zhang, S. (1987). Cognitive complexity and written production of English as a second language. Language Learning, 37(4). 469-481. 
75

APPENDIX A

END OF TERM QUESTIONNAIRE 
Journal Questionnaire

Optional

1. When you write in your journal, do you like to have the teacher give you a topic, or do you like to choose your own topic?

2. What kind of topic do you prefer writing on most: class readings, relating my culture to class topics, or my life/class experiences?

3. Why do you prefer this topic?

4. Which journal assignment do you think is the best?:

5. Which journal assignment did you enfoy writing the most?

6. Do you spend as much time on fournal assignments as on graded work?

7. Do you read the teacher's comments? If so, do you ever answer her questions? Why or why not? 
8. Do you prefer journal writing or essay writing? Why?

$q$. Have you ever written in a journal before you took this class? If yes, where, when?

10. Do you keep a personal journal? (not for class) If yes, do you write in English or in your native language?

11. Would you like to keep a journal next quarter? Why or why not?

12. What did you like or not like about keeping fournals this guarter?

THANK YOU FOR YOUR HELP!

If you have more comments, please write them on the back side of this paper. 
APPENDIX B

JOURNAL HANDOUT 


\section{Speaking and Listening 3 Dialogue writing journals}

Journals are a place for you to show me your knowledge or opinion on a topic. in such a large class, it is difficult to get to know and talk with each student. Journals help the teacher and the student to get to know each other better. In addition, journals are a way of checking to see if you have understood class discussions, assignments or have any questions or comments. Finally, journals are a place for you to experiment with language, test idioms or as questions about words and expressions you encounter in everyday life.

Remember, journals are informal writing, try to write as you speak and don't worry too much about grammar. Sometimes I will assign topics, other times, I will let you choose your own topic or tell about something in your daily life. Try to write about one page; you're always welcome to write more! Finally, journals are required, as they are often your only homework. Although I don't grade your journals, 1 do check to see if they are written. I will read and comment on journals on a weekly basis, usually collecting them on Wednesdays.

Thank you for your cooperation,

Kathryn Brunette 
APPENDIX C

CONSENT FORM FOR JOURNAL USE 
CONSENT FORM FOR JOURNAL USE

1

agree to take part in this research project on journal topics and student response.

(name)

I understand that as part of this study that Kathryn Brunette will photocopy and study my journal entries for her master's thesis research.

I understand that others may read my journal entrles, but that my name will not be known to anyone except the researcher.

In addltion, at the end of the term, Kathryn Brunette will ask me to answer a list of questions about my feellings toward journals and journal toplos. This is to heip the researcher in the study.

Kathryn Brunette has told me the purpose of the study is to learn what kind of journal topics produce the longest and best responses and which toples students prefer. I know this study may not benefit me directly, but may help other ESL teachers and students in the future.

Kathryn Brunette has offered to answer any questlons I have about the study and about what I will need to do.

She has promised that no one will know my name and the Informatlon collected will only be used for the purposes mentioned above.

I understand that I do not have to participate in this study and may quit at any time without hurting my course grade or relationship with Portland State Universlty in any way.

I have read and understand the above information and agree to take part in this study.

Date

Signature

If you have concerns or questions about this study, please contact the Chair of the Human Subjects Research Revlow Committe日, Otfice of Research and Sponsored Projects, 105 Neuberger Hall, Porlland State University, (503) 725-3417. 
APPENDIX D

JACOBS ET AL. (1981) COMPOSITION PROFILE 
ESL COMPOSITION PROFILE

STUDENT

DATE

TOPIC

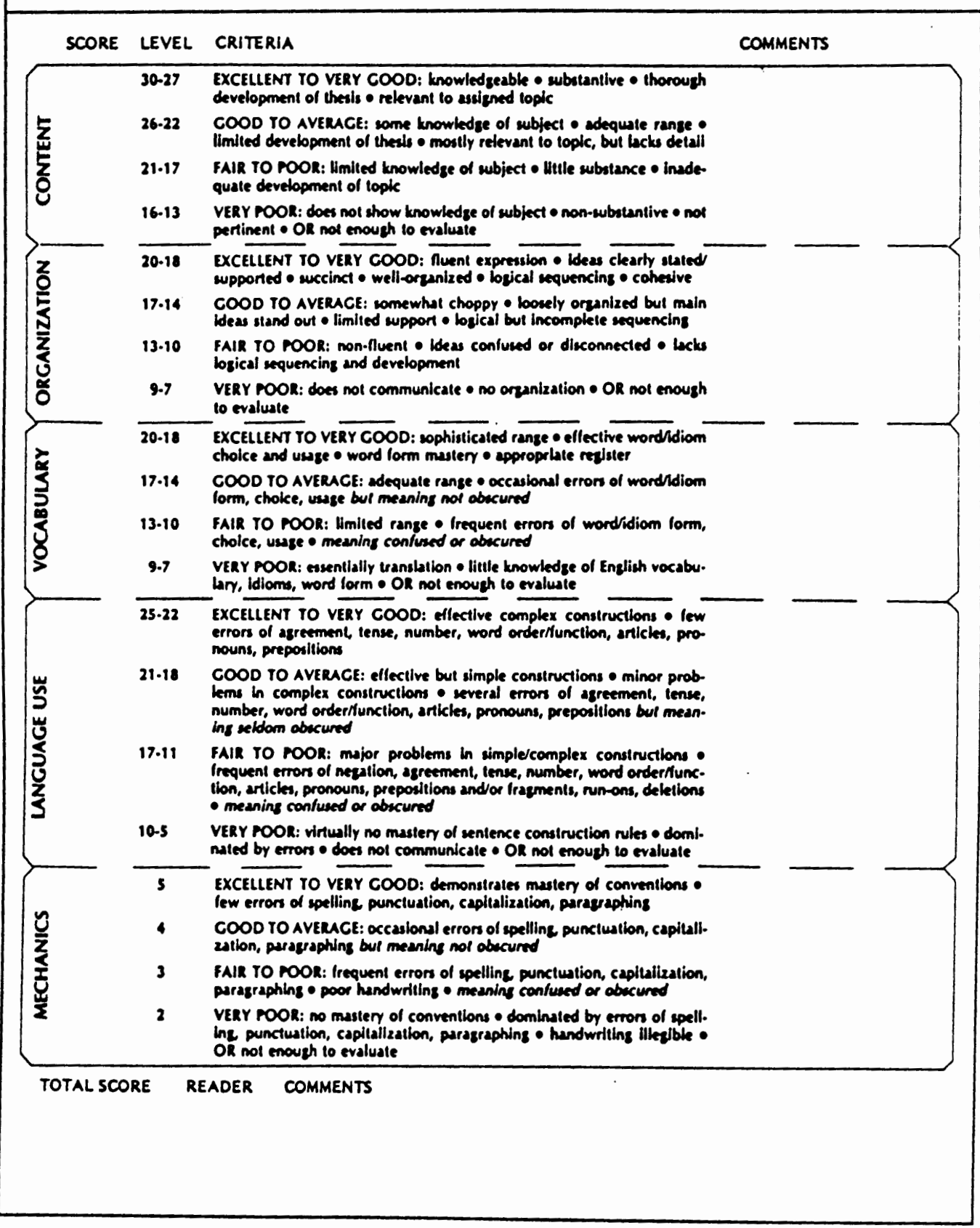


APPENDIX E

VASSILI'S RESULTS 
INDIVIDUAL STUDENT RESULTS FOR VASSILI

\section{TYPEA TOPICS}

\begin{tabular}{|c|c|c|c|c|}
\hline Journal entry \# & Total words & $T$-units & T-unit length & Jacobs ** \\
\hline $\begin{array}{l}2 \\
3 \\
5 \\
14\end{array}$ & $\begin{array}{c}- \\
102 \\
143 \\
135\end{array}$ & $\begin{array}{l}6^{-} \\
13 \\
14\end{array}$ & $\begin{array}{l}- \\
17.7 \\
11 \\
9.6\end{array}$ & $\begin{array}{l}- \\
61 \\
69 \\
65\end{array}$ \\
\hline Average & 126.7 & 11 & 12.8 & 65 \\
\hline \multicolumn{5}{|c|}{ TYPE B TOPICS } \\
\hline $\begin{array}{l}1 \\
7 \\
11 \\
16\end{array}$ & $\begin{array}{c}96 \\
147 \\
- \\
-\end{array}$ & $\begin{array}{l}9 \\
12 \\
- \\
-\end{array}$ & $\begin{array}{c}10.7 \\
12.3 \\
- \\
-\end{array}$ & $\begin{array}{c}60 \\
70 \\
- \\
-\end{array}$ \\
\hline Average & 121.5 & 10.5 & 11.5 & 65 \\
\hline \multicolumn{5}{|c|}{ TYPECTOPICS } \\
\hline $\begin{array}{l}6 \\
9 \\
10 \\
13 \\
15\end{array}$ & $\begin{array}{c}91 \\
- \\
- \\
114 \\
-\end{array}$ & $\begin{array}{c}7 \\
- \\
10 \\
-\end{array}$ & $\begin{array}{c}13 \\
- \\
\dot{11.4} \\
-\end{array}$ & $\begin{array}{c}64 \\
- \\
- \\
67 \\
-\end{array}$ \\
\hline Average & 102.5 & 8.5 & 12.2 & 65.5 \\
\hline \multicolumn{5}{|c|}{ TYPEDTOPICS } \\
\hline $\begin{array}{l}4 \\
8 \\
12\end{array}$ & $\begin{array}{l}95 \\
231 \\
133\end{array}$ & $\begin{array}{l}10 \\
22 \\
14\end{array}$ & $\begin{array}{l}9.5 \\
10.5 \\
9.5\end{array}$ & $\begin{array}{l}67 \\
74 \\
71\end{array}$ \\
\hline Average & 153 & 15.3 & 9.8 & 70.7 \\
\hline
\end{tabular}


APPENDIX $F$

INNA'S RESULTS 
INDIVIDUAL STUDENT RESULTS FOR INNA

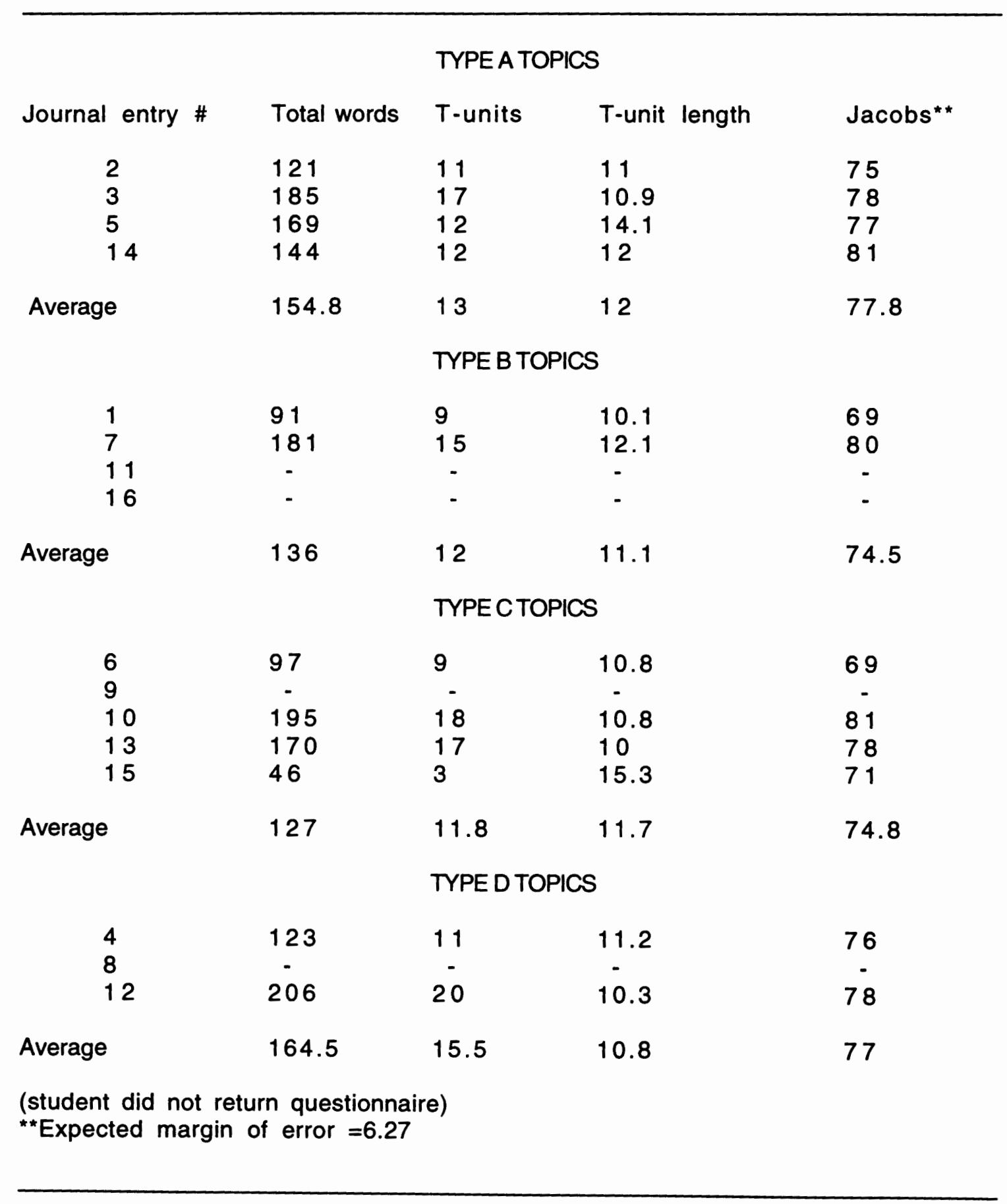


APPENDIX G

YOKO'S RESULTS 
INDIVIDUAL STUDENT RESULTS FOR YOKO

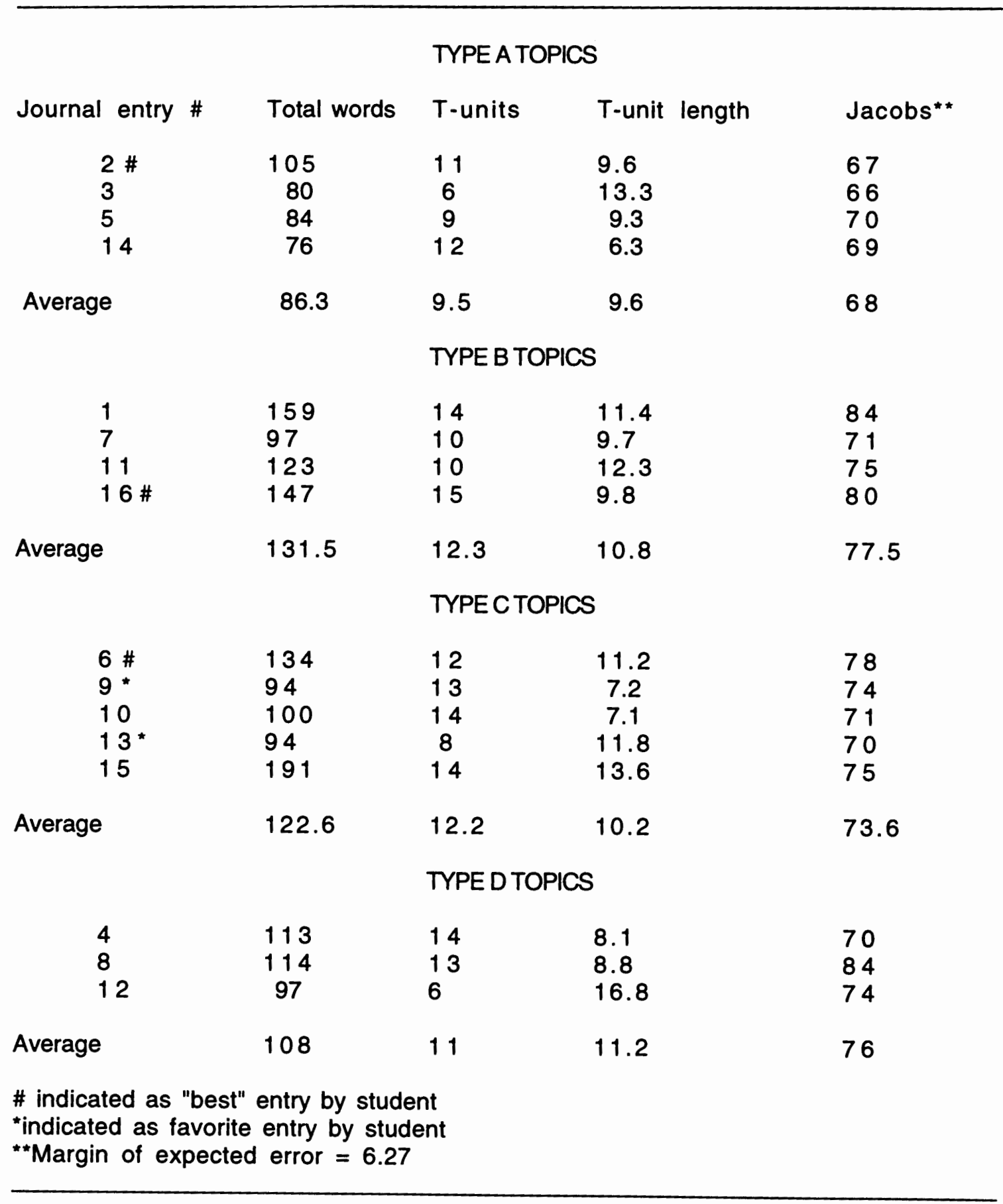


APPENDIX $\mathrm{H}$

JAMES' RESULTS 
INDIVIDUAL STUDENT RESULTS FOR JAMES

\begin{tabular}{|c|c|c|c|c|}
\hline \multicolumn{5}{|c|}{ TYPE A TOPICS } \\
\hline Journal entry \# & Total words & T-units & T-unit length & Jacobs ${ }^{\star \star}$ \\
\hline $\begin{array}{l}2 \\
3 \\
5 \\
14\end{array}$ & $\begin{array}{l}109 \\
101 \\
139 \\
96\end{array}$ & $\begin{array}{l}13 \\
9 \\
13 \\
11\end{array}$ & $\begin{array}{l}8.4 \\
11.2 \\
10.7 \\
8.8\end{array}$ & $\begin{array}{l}67 \\
66 \\
79 \\
68\end{array}$ \\
\hline Average & 111.3 & 11.5 & 9.8 & 70 \\
\hline \multicolumn{5}{|c|}{ TYPE B TOPICS } \\
\hline $\begin{array}{l}1 \\
7 \\
11 \# \\
16\end{array}$ & $\begin{array}{l}132 \\
115 \\
83 \\
75\end{array}$ & $\begin{array}{l}15 \\
12 \\
11 \\
10\end{array}$ & $\begin{array}{l}8.8 \\
9.6 \\
7.6 \\
7.5\end{array}$ & $\begin{array}{l}68 \\
62 \\
69 \\
75\end{array}$ \\
\hline Average & 101.3 & 12 & 8.4 & 68.5 \\
\hline \multicolumn{5}{|c|}{ TYPE CTOPICS } \\
\hline $\begin{array}{l}6 \\
9 \\
10 \\
13 \\
15\end{array}$ & $\begin{array}{l}94 \\
121 \\
108 \\
121 \\
137\end{array}$ & $\begin{array}{l}11 \\
15 \\
12 \\
13 \\
20\end{array}$ & $\begin{array}{l}8.6 \\
8.1 \\
9 \\
9.3 \\
6.6\end{array}$ & $\begin{array}{l}70 \\
70 \\
72 \\
72 \\
78\end{array}$ \\
\hline Average & 116.2 & 10.6 & 8.3 & 72.4 \\
\hline \multicolumn{5}{|c|}{ TYPED TOPICS } \\
\hline $\begin{array}{l}4^{\star} \\
8 * \\
12^{*}\end{array}$ & $\begin{array}{l}137 \\
113 \\
123\end{array}$ & $\begin{array}{l}20 \\
15 \\
10\end{array}$ & $\begin{array}{l}6.7 \\
7.5 \\
12.3\end{array}$ & $\begin{array}{l}86 \\
72 \\
73\end{array}$ \\
\hline Average & 124.3 & 15 & 8.8 & 77 \\
\hline $\begin{array}{l}\text { \# indicated as "be } \\
\text { *indicated as favo } \\
\text { * } \text { "expected margil }\end{array}$ & $\begin{array}{l}\text { entry by stud } \\
\text { entry by stud } \\
\text { error }=6.27\end{array}$ & & & \\
\hline
\end{tabular}


APPENDIX I

ILENA'S RESULTS 
INDIVIDUAL STUDENT RESULTS FOR ILENA

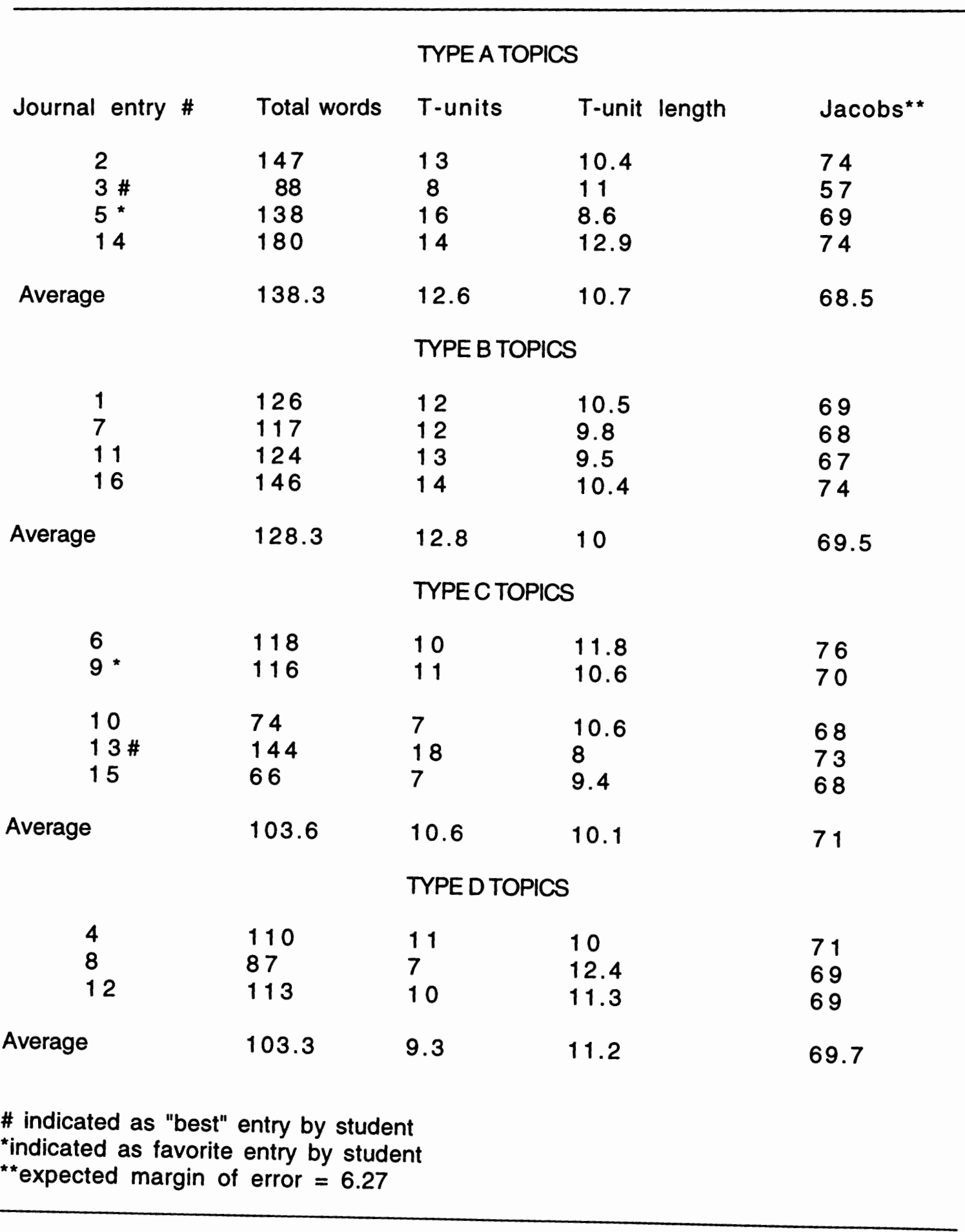


94

APPENDIX $J$

THOMAS' RESULTS 
INDIVIDUAL STUDENT RESULTS FOR THOMAS

\section{TYPE A TOPICS}

\begin{tabular}{|c|c|c|c|c|}
\hline Journal entry \# & Total words & $T$-units & T-unit length & Jacobs ** \\
\hline $\begin{array}{l}2 \\
3 \\
5 \#^{*} \\
14\end{array}$ & $\begin{array}{c}116 \\
130 \\
122 \\
-\end{array}$ & $\begin{array}{l}9 \\
16 \\
12 \\
-\end{array}$ & $\begin{array}{l}12.9 \\
8.3 \\
10.2 \\
.\end{array}$ & $\begin{array}{l}75 \\
71 \\
81 \\
-\end{array}$ \\
\hline \multirow[t]{2}{*}{ Average } & 122.7 & 12.3 & 10.5 & 75.7 \\
\hline & & \multicolumn{2}{|c|}{ TYPE B TOPICS } & \\
\hline $\begin{array}{l}1 \\
7 \\
11 \\
16\end{array}$ & $\begin{array}{l}- \\
99 \\
129 \\
138\end{array}$ & $\begin{array}{c}- \\
7 \\
12 \\
13\end{array}$ & $\begin{array}{l}- \\
14.4 \\
10.8 \\
10.6\end{array}$ & $\begin{array}{l}69 \\
69 \\
75\end{array}$ \\
\hline \multirow[t]{2}{*}{ Average } & 122 & 10.7 & 11.9 & 71 \\
\hline & & \multicolumn{2}{|c|}{ TYPECTOPICS } & \\
\hline $\begin{array}{l}6 \\
9 \\
10 \\
13 \\
15\end{array}$ & $\begin{array}{l}118 \\
115 \\
96 \\
150 \\
99\end{array}$ & $\begin{array}{l}8 \\
12 \\
11 \\
13 \\
6\end{array}$ & $\begin{array}{l}14.8 \\
9.6 \\
8.7 \\
11.5 \\
16.5\end{array}$ & $\begin{array}{l}85 \\
79 \\
74 \\
83 \\
78\end{array}$ \\
\hline \multirow[t]{2}{*}{ Average } & 115.6 & 10 & 12.2 & 79.8 \\
\hline & & \multicolumn{2}{|c|}{ TYPE D TOPICS } & \\
\hline $\begin{array}{l}4 \\
8 \\
12\end{array}$ & $\begin{array}{l}153 \\
100 \\
138\end{array}$ & $\begin{array}{c}12 \\
9 \\
11\end{array}$ & $\begin{array}{l}12.6 \\
11.1 \\
12.6\end{array}$ & $\begin{array}{l}70 \\
73 \\
78\end{array}$ \\
\hline Average & 130.3 & 10.6 & 12.1 & 73.7 \\
\hline
\end{tabular}


APPENDIX K

HISAYO'S RESULTS 


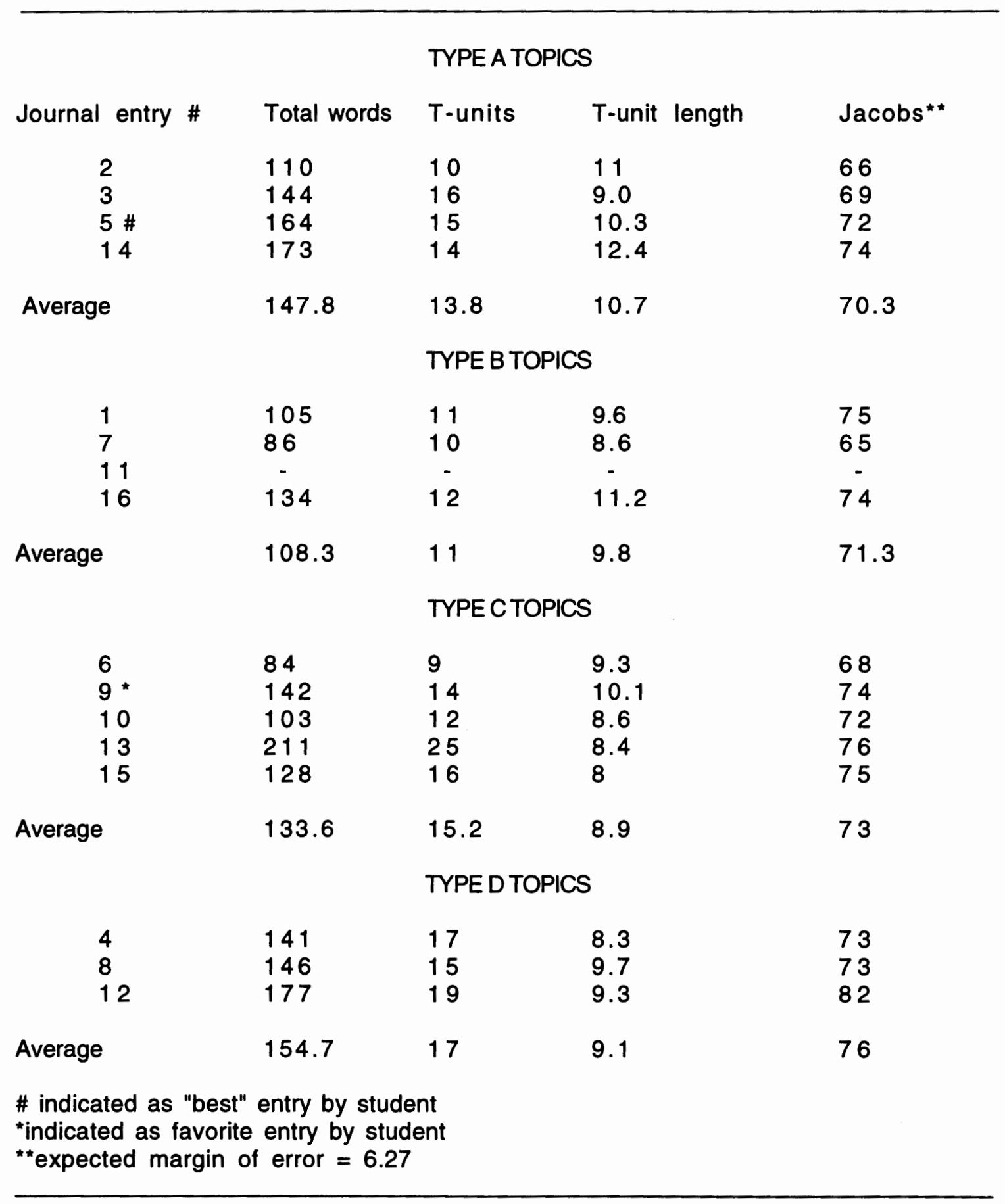


APPENDIX L

FRANÇOIS' RESULTS 
INDIVIDUAL STUDENT RESULTS FOR FRANÇOIS

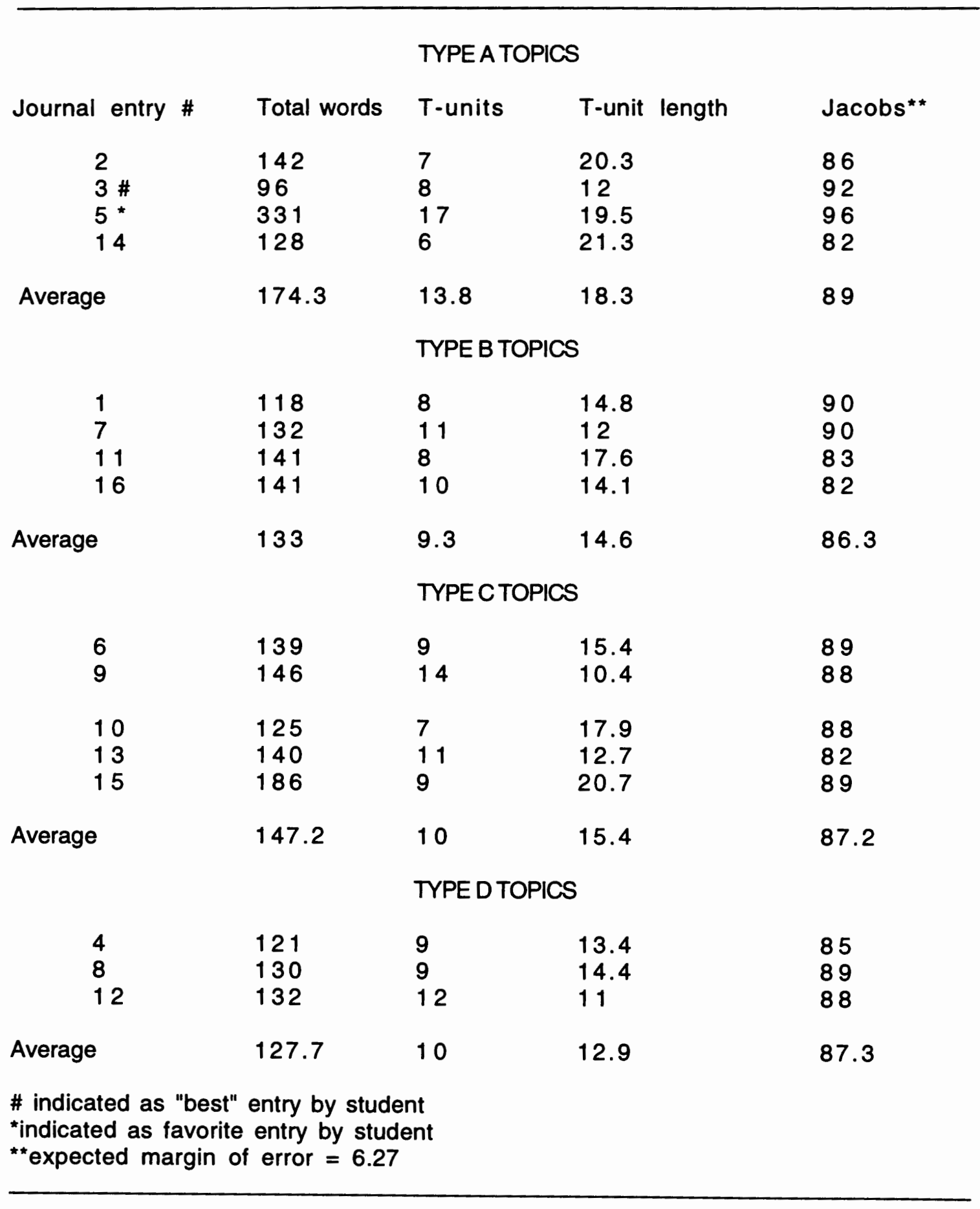


APPENDIX $M$

DANNY'S RESULTS 
INDIVIDUAL STUDENT RESULTS FOR DANNY

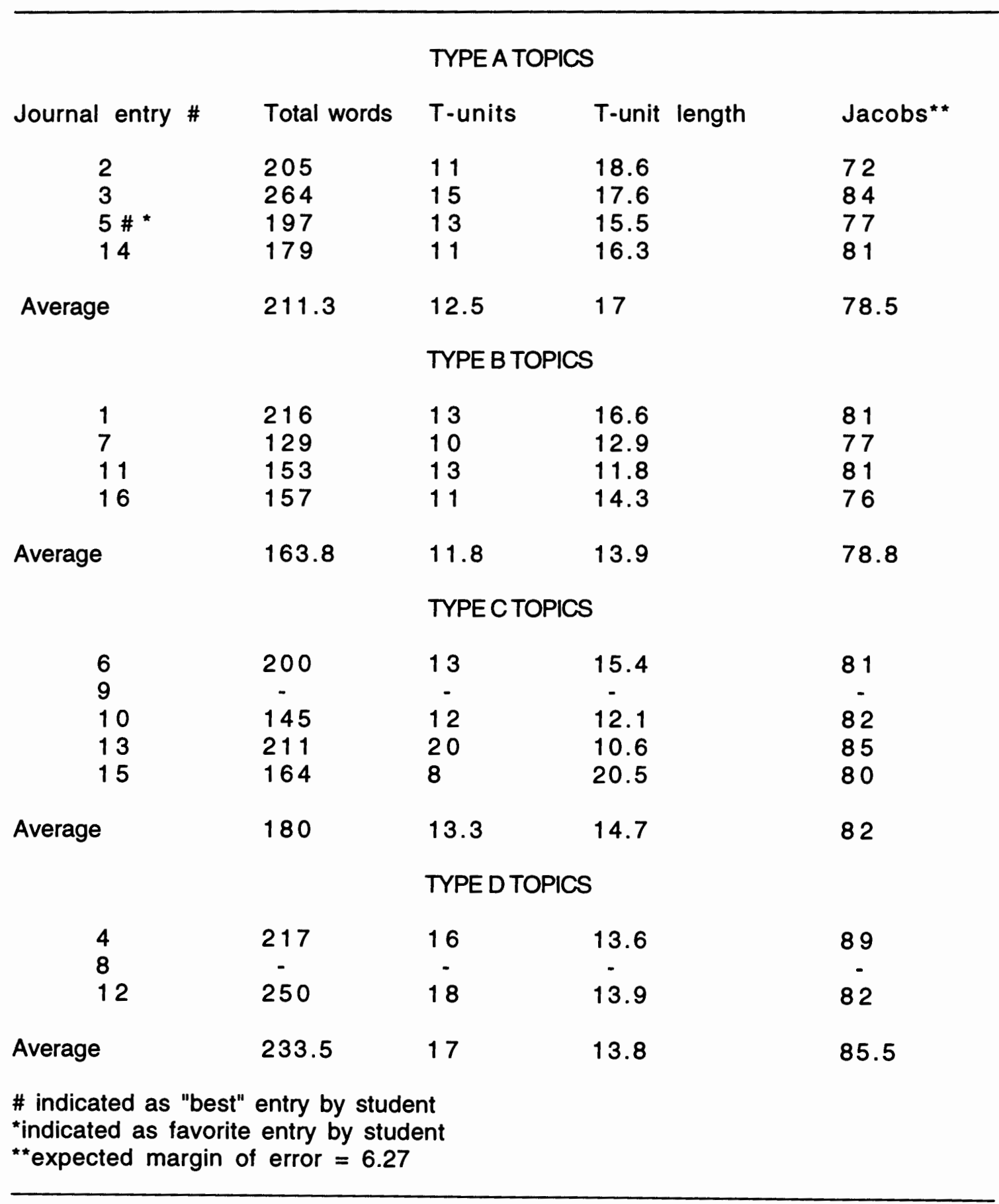




\section{APPENDIX N}

NIKO'S RESULTS 
INDIVIDUAL STUDENT RESULTS FOR NIKO

\begin{tabular}{|c|c|c|c|c|}
\hline \multicolumn{5}{|c|}{ TYPE A TOPICS } \\
\hline Journal entry \# & Total words & T-units & T-unit length & Jacobs** \\
\hline $\begin{array}{l}2 \\
3 \\
5 \# \\
14\end{array}$ & $\begin{array}{l}98 \\
189 \\
329 \\
141\end{array}$ & $\begin{array}{l}11 \\
21 \\
27 \\
14\end{array}$ & $\begin{array}{l}8.9 \\
9.0 \\
12.2 \\
10.1\end{array}$ & $\begin{array}{l}79 \\
80 \\
101 \\
79\end{array}$ \\
\hline Average & 189.3 & 18.3 & 10.1 & 84.8 \\
\hline \multicolumn{5}{|c|}{ TYPE B TOPICS } \\
\hline $\begin{array}{l}1^{*} \\
7^{*} \# \\
11^{*} \\
16^{*}\end{array}$ & $\begin{array}{l}150 \\
379 \\
259 \\
349\end{array}$ & $\begin{array}{l}14 \\
26 \\
23 \\
34\end{array}$ & $\begin{array}{l}10.8 \\
14.6 \\
11.3 \\
10.3\end{array}$ & $\begin{array}{l}79 \\
93 \\
91 \\
95\end{array}$ \\
\hline Average & 284.3 & 24.3 & 11.8 & 89.5 \\
\hline \multicolumn{5}{|c|}{ TYPECTOPICS } \\
\hline $\begin{array}{l}6 \\
9 \\
10 \\
13 \\
15\end{array}$ & $\begin{array}{c}113 \\
293 \\
167 \\
158 \\
-\end{array}$ & $\begin{array}{c}11 \\
32 \\
17 \\
15 \\
-\end{array}$ & $\begin{array}{c}10.3 \\
9.2 \\
9.8 \\
10.5 \\
-\end{array}$ & $\begin{array}{l}84 \\
89 \\
85 \\
77 \\
-\end{array}$ \\
\hline Average & 182.8 & 18.8 & 10 & 83.8 \\
\hline \multicolumn{5}{|c|}{ TYPE D TOPICS } \\
\hline $\begin{array}{l}4 \\
8 \\
12\end{array}$ & $\begin{array}{l}248 \\
165 \\
240\end{array}$ & $\begin{array}{l}22 \\
18 \\
21\end{array}$ & $\begin{array}{l}11.3 \\
9.2 \\
11.4\end{array}$ & $\begin{array}{l}82 \\
80 \\
89\end{array}$ \\
\hline Average & 217.7 & 20.3 & 10.6 & 83.7 \\
\hline $\begin{array}{l}\text { \# indicated as "be } \\
\text { *indicated as favo } \\
\text { **expected margi }\end{array}$ & $\begin{array}{l}\text { entry by stud } \\
\text { entry by stuc } \\
\text { error }=6.27\end{array}$ & & & \\
\hline
\end{tabular}


APPENDIX O

TYPE A ENTRY SAMPLES 
105

$\# 3$

1. learned the origin of Martin Luther. Day."

2 He was a minister the made a speech

3 before Linen toll. He would like to let every

4 black person get free. It was a very impotent

5 politic a movement fur freedom 1 also listened

6 To the tope of the speech. It was an/ exciting

7 speech because a lot of yell was from people.

\& la it was a long speech. I tried to listen corrtull,

sort ${ }^{\circ}$ but I would not understand every detail of

10 sentences By listening to the tape la so had

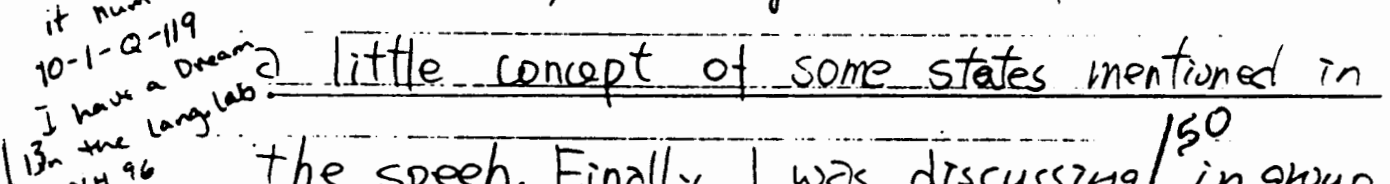

$1213^{\text {Nit }}$ ab the speech. Finally I was discussing ing loup.

Everyone in class had to answer questions

14

written on blackboard. Some questions were not

15

easy to figure out but it was good to shan

is the other classmates' opinions. 30

Ism glad you liked hives

class. It was had to find 


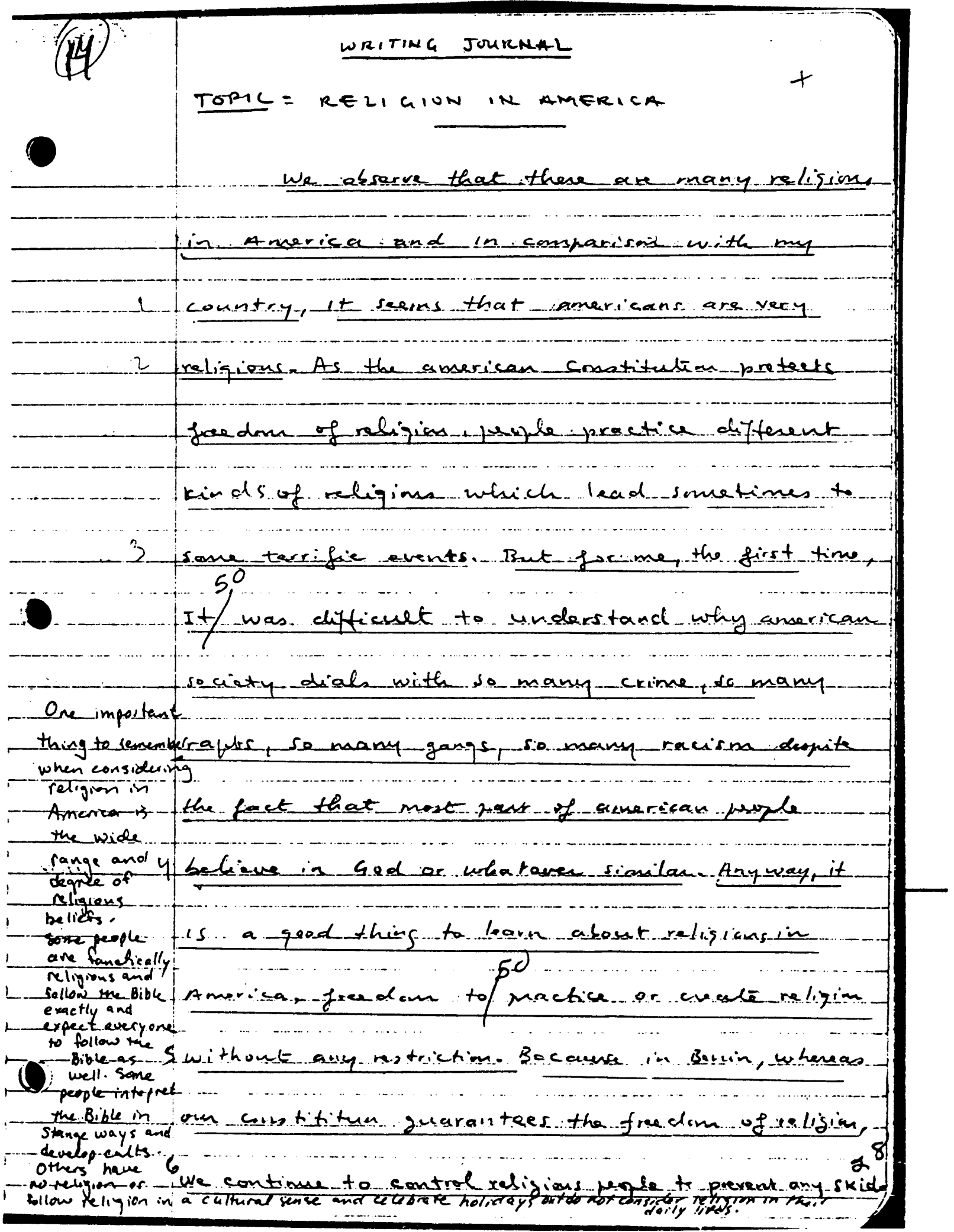


APPENDIX $P$

TYPE B ENTRY SAMPLES 
108

Immigration trends in Any country I think that after WWII for several

- year, immigration to Japan ins a few. But after sconiowice growth in Dem, the umber of immigration also grass sp,

speciality refugees Dunn increasing ecenemic growth

up economic in Japan, a lot of seffregeas

3 came to Japan lay bout. sh had not

415 engine |'. They had not food. Their come from their country at the sister of

- their life. O forget that spice sucre

- they from. But I think they sure.

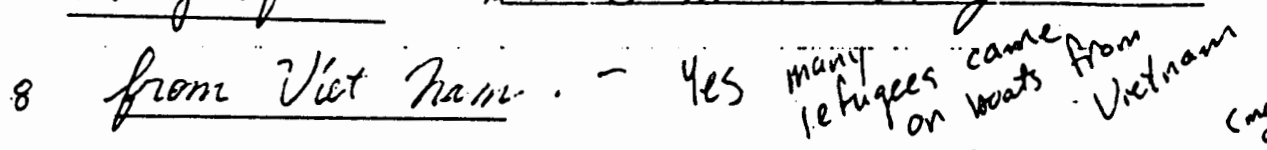

how, in Japan, economic bell down (declined)

9 gradually. At I think that the number

is of 'min gratian will fall down: / 47

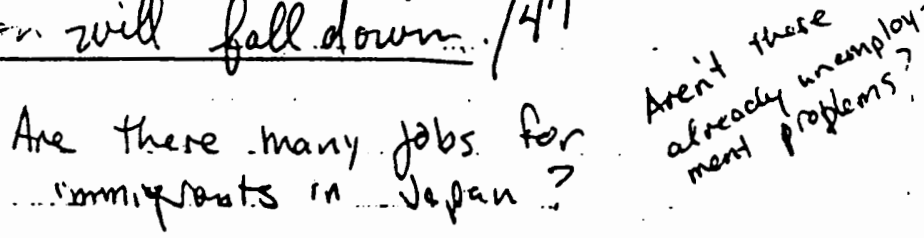




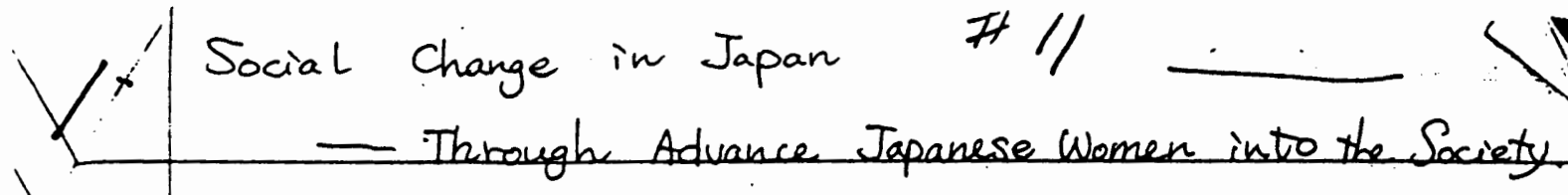
Tapanese women had some chances for entering

. Japanese society.

First, it was at $1870 \sim 1918$ (Since 1868,

as Japanese were influenced by Europe, especially

Germany and England, they imitated many kind

3 of systerass of them. After Industrial Revolution

in England, Japanese made factories and

- 4 young women worked these It was 50 so hand want

5 that mojority of women were sick ar dead.

6 Next chance came at $1918 \sim 1937$. It

was the times between World War I and World

18 War I. It was comparatively peaceful time.

Some womex began to work as bus conductresses,

9 waitresses in European style's cafe or teachers.

- They were called "Modern girls in Taishe Pexied." At the same time, Taisho period produced many 


Social Change In Japan
(cont.)

is wheir houses. And Japarese had baby boom.

Finally, It was Woman's Liberation Morement.

"Ifow the 11.5. Those whe were bork in the baby

18, boom were influenced by Woman's Lib. in 1970's They took an active $\left.\right|^{\circ}$ part in Japanese Saciety and

19) made way for youngex women.

$\langle$ Percentage of female Workers in Major Industries >

$\begin{array}{llllll} & 1975 & 1980 & 1985 & 1990 & 1992 \\ \text { All industries } & 322 & 34.1 & 35.9 & 37.9 & 38.6\end{array}$

Constreaction $\quad \begin{array}{lllllll}3.0 & 13.6 & 13.8 & 15.6 & 16.3\end{array}$

$\begin{array}{llllll}\text { Manufacturing } & 31.7 & 34.0 & 35.2 & 36.1 & 35.7\end{array}$

$\begin{array}{lllllll}\text { Trouspertation, communiation } 12.1 & 11.8 & 12.7 & 14.4 & 16.3\end{array}$

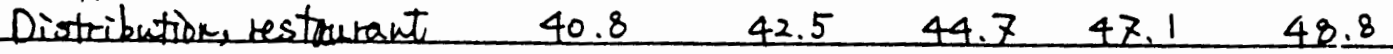

Financial, real estate. $\quad 45.2 \quad 46.3 \quad 45.2 \quad 50.2 \quad 50.4$

\begin{tabular}{llllll} 
Service & 47.3 & 49.2 & 49.4 & 49.6 & 50.2 \\
\hline
\end{tabular} 
111

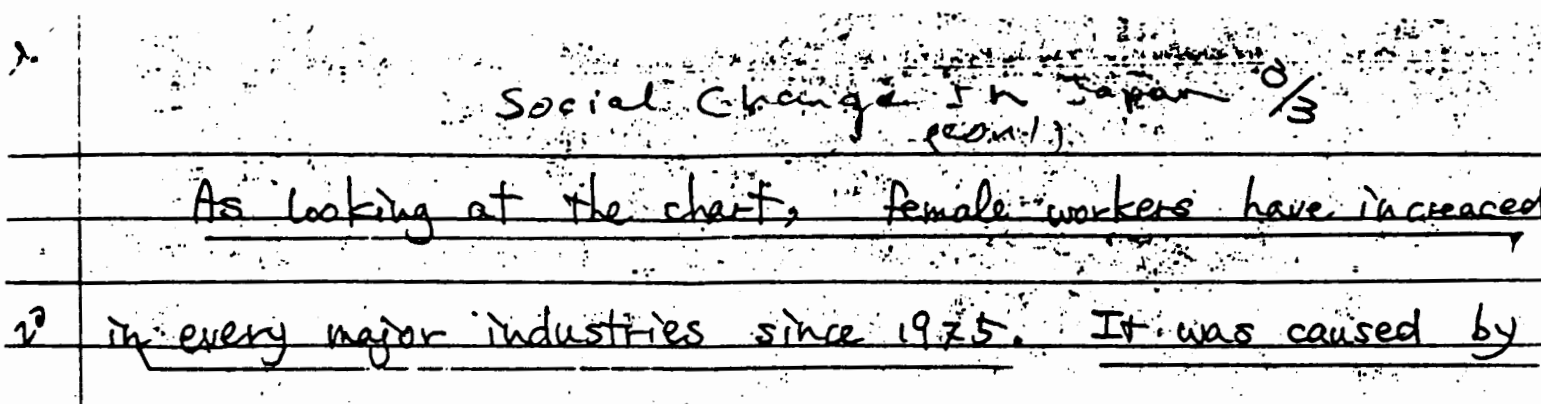
the shortage of labor force because if rap economic

2) growth in recent years. But Japanese economic has

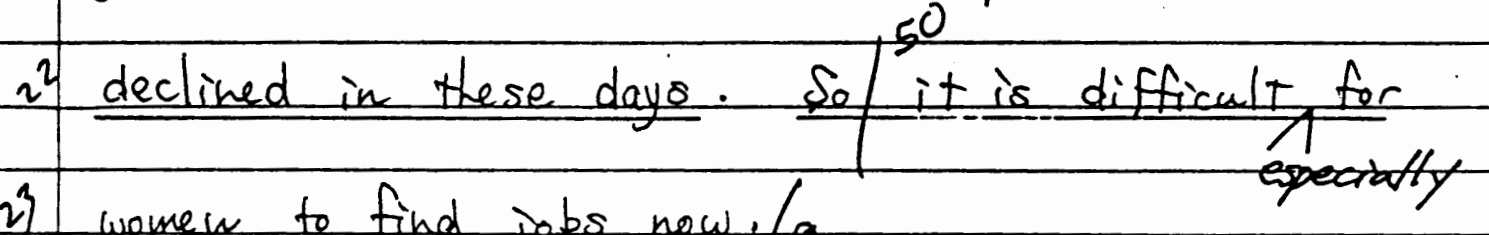

2) women to find jobs now. $/ 9$

Just women?

or is unemployment

a general problem? 
APPENDIX $Q$

TYPE D ENTRY SAMPLES 
113

$$
\$ 4
$$

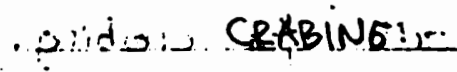

oust friday, after: I finishes my all

1 Classes, I went home ono - watching IV f p and as soon as the time wot $06: 30 \mathrm{Pm}$. - my brother my sister...

ono I went to watched Te - kwon-do exhibition

2 in the memorial coliseum. The exhibition wop very interesting show to watch, because all the / peoples who is trying to move an exhibition ligtesting were 3 Korean people

- -... Later after. I finishes watching the

4 Toe-kwon-don:exhibition / w want back to my sportmont as soon of possible, because in y third

9 brother and I was decided that we were going to go to Newport for crating on saturday/ morning.

6 .... It took two hour to get there and

1 after we got there I "wot very tiras/so I

recipes to go to be o early, because on saviday 
114

. Crabing

(cont)

8 I should ware up early for crating.

On Saturday morning then we were

- 9. going to renter a boat I fell the warning

10 very coll for me So after we rented the boat

"we also rented I rings for crab., so we were

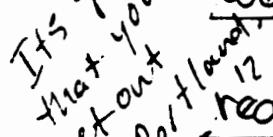
ready to go to crating.

13

in fact we did catch bots of cobs

i in

saciow that we should went back because

$151+1 / 5$ a little to late for crating. So frilly we

16 went back to portland with so crabs f 11

What did you do with obs?

-. all those abs \#

Dies 70 u eat? 
115

$\mathrm{Feb} / 23 / 94$

(your choice) \#12

$\gamma$ In America

If I had not cone to America, I would have

$\checkmark$ wrong opinion about American.

When I was in my country, I only got

2 Information frow TV about America. This made me judging

3 America by appetence Even though I only stayed in

? Portland and only six months, I knew a lite le lit,

4 American culture.

Jane, who invited us to her

hame potluck, is my last term speaking and listening

5 teacher. When I brought chicken wing to her house,

1 she cold me, in formal party, American didn't eat
This checked wing. But in Taiwan, the women like to eat
Somerinies I am not polite to American,

9 because I don't know American culture.

or 11 This takes I wish I could know American culture. $\left.\right|^{23}$ in social situations. like janet. 
116

$\$ 17$

My Choice

$\operatorname{san} 150$

On Saturday we bad a party because ny

... $q$ we old a lot and ate a lot rut mare friend

... will! be graduate an spring terni the tout to

4 know hos caul find the job in America? He told

50

us iil/the America you. must knew how to reccumod

$\$ 16$ yourself. Speaking English is impendent of so we.

7 must improve us English then sens find the job.

8 I usually speak Chinese in my hame but

9 right now I try to speak Bugled in my hour

- 10 I thill te spence English with my timed on family.

- 11 that is geod way re improve pelf biggish 10

also listen to the radio \& television.

try to set time when you must

speak English, for example at

dinner. Or when you go shopping or are in public. Trey to make it a habit I used to do thus when $T$ loved in france. 
117

APPENDIX $R$

TYPE C ENTRY SAMPLES 


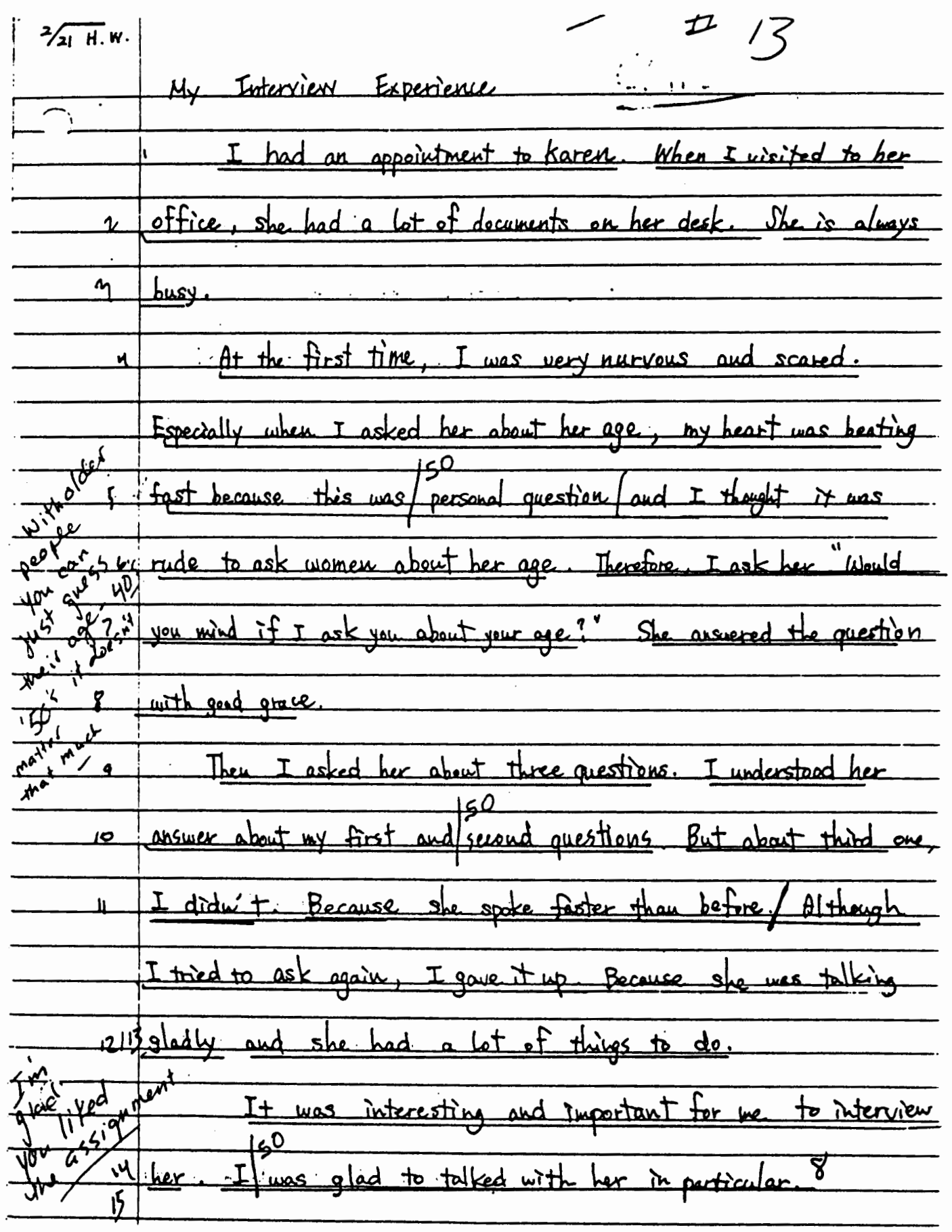


119

\#9

Compranication experience with an American person

First time, when I Talked with an American peof'ess

Wooer' I was strained and my hands were sweaty. I didn't

this 3 completely speak English. I talked host family first time

you might II have a bitter experience at the Taco Bell: I want

want lure 5

to et p pops To Take Bell for lunch with my friend for two/ years a jo.

fol yer you I ordered steak soft taco and chicken sot t taco/so

$\rightarrow$ it might two dollorslbut the lady who worked at loco

8. Bell said 12 dollars or something like it. I wondered

a why I had have to pay 12 dollops, but I gave them

1012 dollars. When I picked/ up my ordered. The rs was 11

112 soft taco and one chicken soft taco. When I asked

13 about it, they said that they thought I raid so.

I took 11 sot taco and one chicken sot t taco and ate

14 them with my friend: $14^{2}$ You see. it's better to ask questions when there is a misunderstanding 
Group presentation

We had a groups presentation in the class last week. Every group had its own topic to 19.present. The group included 3 -4 peopl. Fvery student tolel something about the topic which they hade 4 hosen. After presentation some students from the - class asked them Questions. It was a 900 d idealagrous presentution, however I didn't eike it very much,

7 because sdidn't understand a lot that were saind: I think it is much useful for us to hear a real american speach and to eearn from that

$s$ american prononsiation and other things $\nabla$ understand. that every student in the class schould speak

1 englich, But in such big class like we have it is

1011 in? possible. We have manx students in the class/as a

is resolt we spend a lot of time to hear japanese,

13 Eorean, urrainean speachs and others. These

14 ppeachs are not clear and bagad prononsiation 15 What can we learn from this. How can we improve

16 eur sngeish speaking and eistening. It would

17. be good if there weregfew students in the class. But in this situation J thinh it is better Lor otudents to eisten more cassets and teacher's 16 speach 45 I am sorry abaut $m x$ dowrnal.

Thank you for being honest. Im solvy that you didit like the presentations. but everyane needs ti practice public speoking so the class has to be the andierce I know this is a big class but you can improve 